\title{
Jordan: The Elements of a Growth Strategy
}

Ricardo Hausmann, Tim O'Brien, Miguel Angel Santos, Ana Grisanti, Semiray Kasoolu, Nikita Taniparti, Jorge Tapia, and Ricardo Villasmil

CID Faculty Working Paper No. 346

February 2019

Revised April 2019

(C) Copyright 2019 Hausmann, Ricardo; O'Brien, Tim; Santos, Miguel Angel; Grisanti, Ana; Kasoolu, Semiray; Taniparti, Nikita; Tapia, Jorge; Villasmil, Ricardo and the President and Fellows of Harvard College
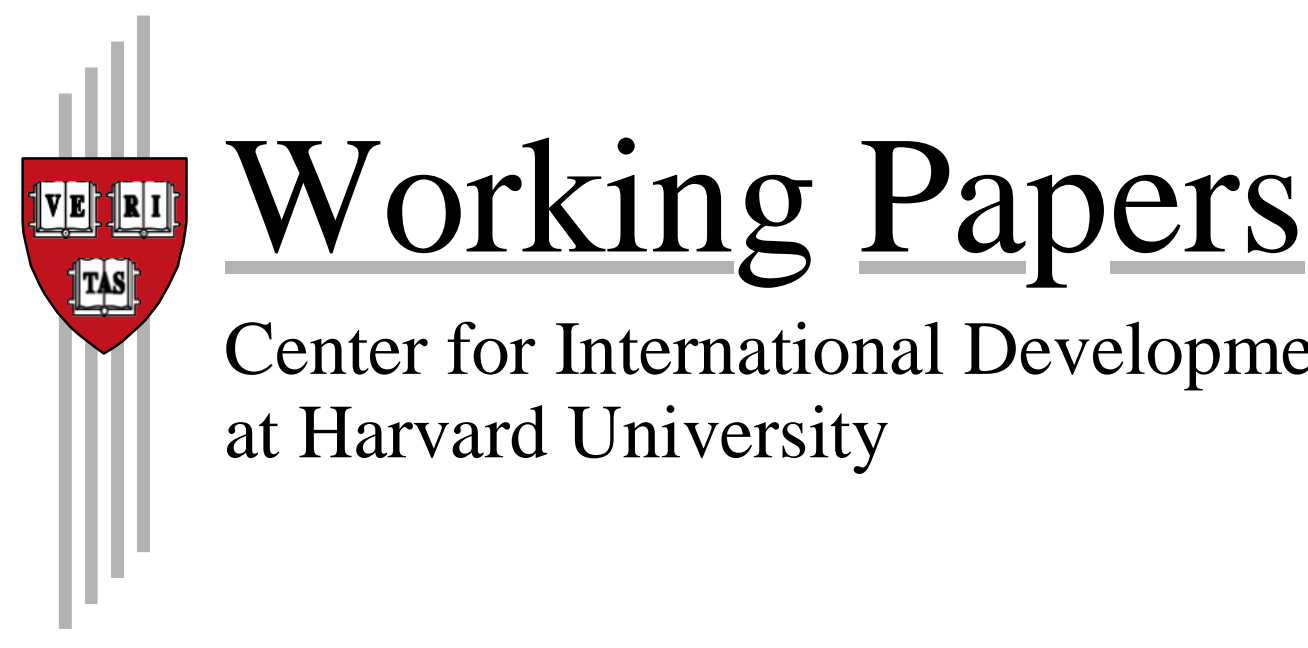

Center for International Development at Harvard University 


\title{
Jordan: The Elements of a Growth Strategy
}

\author{
Ricardo Hausmann, Tim O’Brien, Miguel Angel Santos, Ana Grisanti, Semiray \\ Kasoolu, Nikita Taniparti, Jorge Tapia, and Ricardo Villasmil
}

\begin{abstract}
In the decade 1999-2009, Jordan experienced an impressive growth acceleration, tripling its exports and increasing income per capita by $38 \%$. Since then, a number of external shocks that include the Global Financial Crisis (2008-2009), the Arab Spring (2011), the Syrian Civil War (2011), and the emergence of the Islamic State (2014) have affected Jordan in significant ways and thrown its economy out of balance. Jordan's debt-to-GDP ratio has ballooned from 55\% (2009) to 94\% (2018). The economy has continued to grow amidst massive fiscal adjustment and balance of payments constraints, but the large increase in population - by $50 \%$ between 2008 and 2017 - driven by massive waves of refugees has resulted in a $12 \%$ cumulative loss in income per capita (2010-2017). Moving forward, debt sustainability will require not only continued fiscal consolidation but also faster growth and international support to keep interest payments on the debt contained. We have developed an innovative framework to align Jordan's growth strategy with its changing factor endowments. The framework incorporates service industries into an Economic Complexity analysis, utilizing the Dun and Bradstreet database, together with an evaluation of the evolution of Jordan's comparative advantages over time. Combining several tools to identify critical constraints faced by sectors with the greatest potential, we have produced a roadmap with key elements of a strategy for Jordan to return to faster, more sustainable and more inclusive growth that is consistent with its emerging comparative advantages.
\end{abstract}

JEL classification: E23, E24, E62, E65, J21, J24, J31

Keywords: Jordan, growth, labor markets, female labor, complexity, growth diagnostics, growth accelerations, service exports 


\section{Table of Contents}

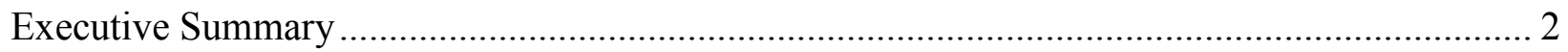

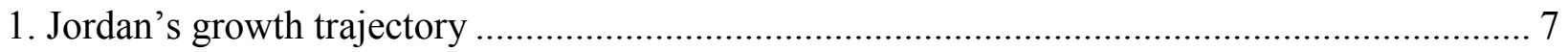

2. External shocks: Impacts on exports and foreign direct investment (FDI) ............................... 9

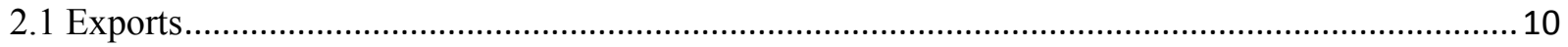

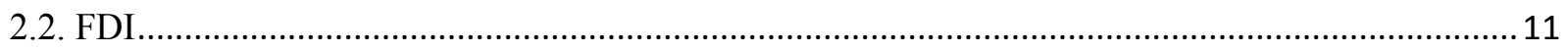

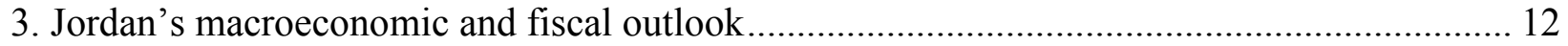

4. An export-led growth strategy: comparative advantage considerations ................................... 16

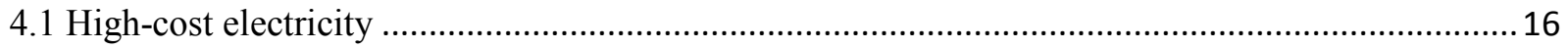

4.2 The odd and changing character of factor endowment: Human Capital .........................................19

4.3 Complementary high-skill immigration ……………………………………………………....2

5. Understanding Economic Complexity inclusive of services ...................................................... 29

5.1. Incorporating goods and services: Dun and Bradstreet dataset …….............................................30

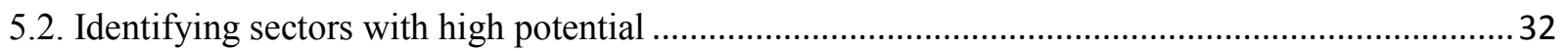

6. Integrating these elements into a framework for growth strategy ............................................. 38

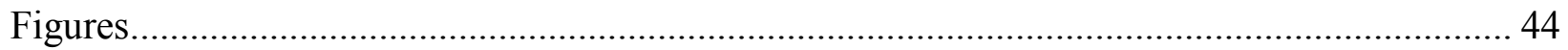

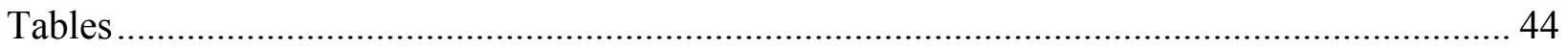

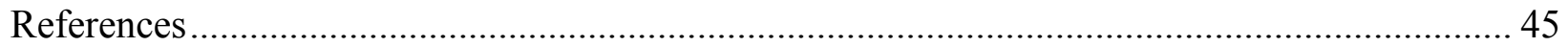

1|Jordan: The Elements of a Growth Strategy 


\section{Executive Summary}

In the decade prior to the global financial crisis of 2008-2009, Jordan enjoyed a period of impressive macroeconomic performance. The prolonged expansion was export-led, with total exports of goods and services tripling over that period. The boom was not only due to better prices for Jordan's exports, as there were significant gains in global market share of Jordan's garment, agriculture and chemical exports. Throughout these years, the country ran large current account deficits that were mostly financed by massive inflows of foreign direct investment (FDI) coming from the United Arab Emirates, the United States, India, Bahrain and Saudi Arabia. By the end of 2009 , the size of total public debt was moderate: $55 \%$ of the Jordanian economy.

The global financial crisis of 2008-2009 and a series of subsequent negative external shocks affected the Jordanian economy in significant ways. Conflict in neighboring countries led to reduced demand from key export markets and cut off important trade routes. FDI, which averaged $12.7 \%$ of gross domestic product (GDP) between 2003-2009, fell to 5.1\% of GDP over the 2010-2017 period. Regional conflict also provoked a massive influx of migrants and refugees which resulted in a net population increase of 50.4\% between 2008 and 2017. Instability also severely impacted the cost of energy. The supply of oil from Iraq in concessional terms came to an end in 2004, and the Egyptian natural gas pipeline suffered numerous disruptions in 2011, forcing Jordan to import expensive liquid fuels at a time of record prices, furthering pressures on its balance of payment and fiscal accounts. This shock had significant effects on electricityintensive Jordanian manufacturing.

Export growth initially only decelerated between 2009 and 2013, as global trade slowed down and Jordan's market share gains in garment and chemical exports stagnated. Then, between 2014 and 2016, exports plummeted by 13\% as trade with and through Iraq and Syria collapsed. The downturn was particularly sharp in agriculture, transport and tourism. As a consequence of these external shocks, imports fell along with exports - by 2017, they were 20\% down from 2014 levels in real per capita terms, $44 \%$ below their 2008 peak.

The deceleration of export-led growth and the dramatic fall in imports had an important negative impact on tax revenues. To confront this situation, the country implemented a massive reduction in its fiscal impulse - domestic spending net of domestic revenue - of $8.1 \%$ between 2011-2017. This substantial adjustment was accomplished by increasing indirect taxes, eliminating subsidies, and cutting down on public investment. The six-year adjustment was significantly larger than those registered in Spain (4.6\% of GDP, 2009-2015) and Portugal (6.1\%, 2010-2016), and not far below the one recorded in Greece $(10.7 \%, 2010-2016)$.

In the context of such a large fiscal consolidation, Jordan's economy has displayed extraordinary resilience, growing at an average yearly rate of $2.5 \%$ over 2011-2017. However, 
because of the extraordinary rate of population increase, this translated into a significant contraction of $10 \%$ in per capita income over the same period. Unemployment has risen to $18.7 \%$ by theend of 2017 , and is particularly high among women $(28.1 \%)$ and youth $(39.7 \%)$.

In spite of the massive fiscal adjustment, Jordan's debt-to-GDP ratio rose from $70.7 \%$ in 2011 to $95.5 \%$ in 2017 . The fact that Jordan was forced to issue debt in Eurobond markets at increasing yields at a time when its economy was not fully stabilized, suggests that the 2012 and 2015 International Monetary Fund (IMF) programs were underfunded. If Jordan continues along this path, the ensuing rise in its debt service burden would make fiscal stabilization even more challenging. In order to allow the country room to implement its growth strategy, the Jordanian government must take steps to finance its declining deficit an roll over its maturing debt without having to resort to the Eurobond market until the economy is fully stabilized.

Given the fiscal restrictions, growth can neither depend on a fiscal stimulus, nor can it be expected to follow from fiscal discipline. The fact that the current account deficit is already large means that growth cannot be led by increases in domestic private demand for non-tradable goods, as these will require more imports that would worsen the external balance. Thus, Jordan's growth strategy must be driven by exports and investment that either directly or indirectly support export growth. Resuming export growth will have a multiplier effect on the non-tradable sector, which has been negatively impacted by the drastic cut in domestic spending.

A few key differences between the present time and the conditions prevailing over the long growth acceleration of 2000-2008 in Jordan are worth mentioning. Regarding the labor market, the most noticeable change since 2008 has been the inflow of refugees. But the country's biggest comparative advantage today is its highly educated workforce - which has been developing over a longer timeframe. What is most striking is the long-term increase of highly educated women. Female tertiary enrollment rate has increased by 30 percentage points in two decades, from $20 \%$ in 1995 to almost $50 \%$ in 2015 . Although the rate has plateaued for several years, this still means that the Jordanian labor force becomes more skilled with every passing year, as the working-age population with a college education converges to this rate. Traditionally, public administration, education and the health sector have been the largest employers of female labor, but given fiscal restrictions, it's unlikely that these sectors can grow enough to absorb the large increase expected in qualified female labor in the coming years. Thus, Jordan needs to create jobs in other tradable goods and services, such as telecommunications, information technology, or - more broadly - the business services sector, that may employ Jordanian women and pay higher wages.

Energy costs in Jordan have also experienced changes since the growth boom: they have risen substantially as the system has adjusted to maintain stability of supply in the face of more expensive energy inputs. Meanwhile, water scarcity, which has long been a disadvantage for Jordan in terms of production inputs, has intensified in recent years as a result of rising costs of 
electricity (used in the filtering and transportation of water) and due to increased demands of a larger population. Thus, in the short term, Jordan must pursue a strategy led by sectors that are not intensive in energy or water. Over time, Jordan should follow a multi-pronged strategy to reduce the cost of electricity in order to drastically expand its comparative advantage. The energy strategy must exploit Jordan's natural advantages for renewable generation and leverage on new technologies to maintain grid stability. This transition will have direct positive benefits on the balance of payments and will open new opportunities for sustainably increasing water supply.

Given these factors, it should come as no surprise that service exports have been more dynamic than goods exports since 2008. Jordan's service exports grew steadily - with a minor hiccup after the financial crisis - from US \$1.6 billion in 2000 to US \$7.1 billion in 2014. Travel, tourism, transportation and logistics delivered the bulk of this growth, but regional instability caused these sectors to stagnate from 2014 onwards. At the same time, Jordan has increasingly emerged as a hub for activities related to information, communications and technology (ICT). In the context of Jordan's overall slowdown since 2008, ICT, along with business services and electricity, remain exceptions in that they have experienced increased FDI flows since 2008

The Center for International Development at Harvard University (CID) developed a tool to perform economic complexity analysis inclusive of services for the first time, and applied it to Jordan. Using this tool to understand existing and latent areas of comparative advantage that can be developed with relative ease by redeploying the knowhow, skills and capacities that the country already has, we have identified eight export themes that have the highest potential to drive growth in Jordan while supporting increasing wage levels and delivering positive spillovers to the nontradable economy: 1) Business, IT and Professional Services, 2) Education Services, 3) Healthcare Services, 4) Creative Industries, 5) Tourism, 6) Transportation and Logistics, 7) Construction Materials and Services, and 8) Agriculture and Food Processing.

The results of this analysis confirmed previous qualitative assessments that identified a strong orientation toward high-skilled, tradable services among Jordan's most strategic sectors. Crosschecking these eight export themes throughout Jordan's economic census and survey data shows that the first four tend to support higher wage levels, require higher levels of education, and employ higher rates of women than the rest of the Jordanian economy, a trend that also matches patterns of more mature economies. Overall, Jordan will tend to compete with richer countries in several of these high-skill, tradable services in order to serve regional and global markets, but Jordan's unusually high human capital as compared to its income level provides a strong cost advantage to companies that need a place to perform relatively labor-intensive tasks. The latter four themes include a mix of low and high-skill labor requirements that also draw upon Jordan's unique geographical advantages. Strong growth in these sectors can support new jobs for Jordanians and non-Jordanians alike.

4|Jordan: The Elements of a Growth Strategy 
These strategic export themes represent a mix of specific industries in which Jordan already has a relatively large presence, as well as industries that are incipient and that display latent capabilities for Jordan according to global patterns. Jordan's abilities to achieve sustainable and inclusive export-led growth will depend on maximizing the potential of both types of industries, accelerating growth in existing sectors (the intensive margin) and attracting new business models that build on Jordan's existing knowhow and capabilities (the extensive margin). For the intensive margin, it is critical that the government works jointly with the private sector in order to understand, and iteratively solve sector-specific constraints to higher productivity and better market access. For the extensive margin, the Government of Jordan as well as donor nations can play an important role in promoting foreign direct investment to jumpstart these industries.

Interviews with existing companies in Jordan as well as econometric analysis, reveal that restrictions on hiring high-skilled workers from abroad who provide the necessary complements to high-skilled Jordanian workers have become a critical constraint to the growth of existing highskill service exports. These restrictions also generate high transaction costs that further hinder growth opportunities. Often, in order to operate, a company needs access to a few individuals with very specific skills that are not available in Jordan. Although a normal and necessary part of innovation, Jordanian labor regulations restrict the hiring of high-skilled foreigners in an attempt to protect Jordanian jobs. This is a problem that is actually costing an untold number of job opportunities for Jordan's best and brightest, while hindering growth for Jordan's most promising tradable industries. The Government of Jordan is currently working to address this issue.

As the government focuses resources on unleashing the competitiveness of these strategic export themes, it must work in close coordination with the private sector to identify other critical constraints to the growth of these sectors and collaborate to address them.

In this regard, it's clear that active and strategic promotion of investment is the most powerful tool for attracting new business models that build on Jordan's existing knowhow and capabilities (the extensive margin). After analyzing foreign investment flows, we found that in any given year, there are hundreds of companies, tens of thousands of jobs, and hundreds of millions of dollars of FDI flowing into the region - and to the UAE in particular - across the eight identified export themes. If Jordan were to attract just a small share of these investment flows, it would significantly boost the development of these activities. The Government of Jordan shall increasingly focus its efforts on actively communicating with targeted companies to provide specific messages on why they can thrive in Jordan and where in the country they can find the required land, infrastructure, and human resources.

Beyond these sector-specific interventions focused on activating stronger growth on the intensive and extensive margin of the private sector, Jordan must improve its ability to deliver 
targeted infrastructure investments, among other public goods and services, that will improve productivity across the board and expand its comparative advantage.

In sum, the growth strategy for Jordan must be cognizant of the fiscal and balance of payments constraints that the country faces. As a consequence, the approach should be export-led, and must leverage on the growth of these activities in order to generate multiplier effects for the rest of the economy. The strategy must acknowledge the worsened competitiveness in electricity and water by promoting high-potential sectors that are not intensive in either of these, but should also consider that new technologies in solar and wind can leverage the country's natural advantages in these areas to lower energy prices. The strategy must also consider the rising share of high-skilled female citizens that are joining the labor force, and the fact that within an environment of fiscal consolidation, the industries that presently employ the bulk of high-skilled female labor education, health and the civil service - are unlikely to expand enough in order to keep up with increased supply of labor. Promotion of export services that are more intensive in high-skilled female labor should be a priority.

The export-led growth strategy must recognize that key infrastructure investments ideally involving private sector capital will be needed. However, it must emphasize the importance of improving the Government of Jordan's project preparation skills, in order to take key ventures from inception to a point where they are effectively investable and bankable. While the program is being implemented, the government must make sure that it's able to fund itself at low interest rates in order to avoid an increase in debt service costs. 


\section{Jordan's growth trajectory}

In the decade prior to the global financial crisis of 2008-2009, Jordan enjoyed a period of impressive macroeconomic performance. GDP grew at an average of $6.5 \%$ per year $-3.4 \%$ in per capita terms - a total cumulative increase in per capita income of $38.0 \%$ between 1999 and 2009. This steep trend came to an end by 2008, a point that reveals the strongest structural break in Jordan's growth data since 1975 (Figure 1). ${ }^{1}$ From then onwards, the financial crisis and a series of negative external shocks - including the Arab Spring and the Syrian refugee crisis - slowed down growth to a yearly $2.5 \%$ over the following nine years (2009-2018).

Figure 1. (Ln) GDP per capita

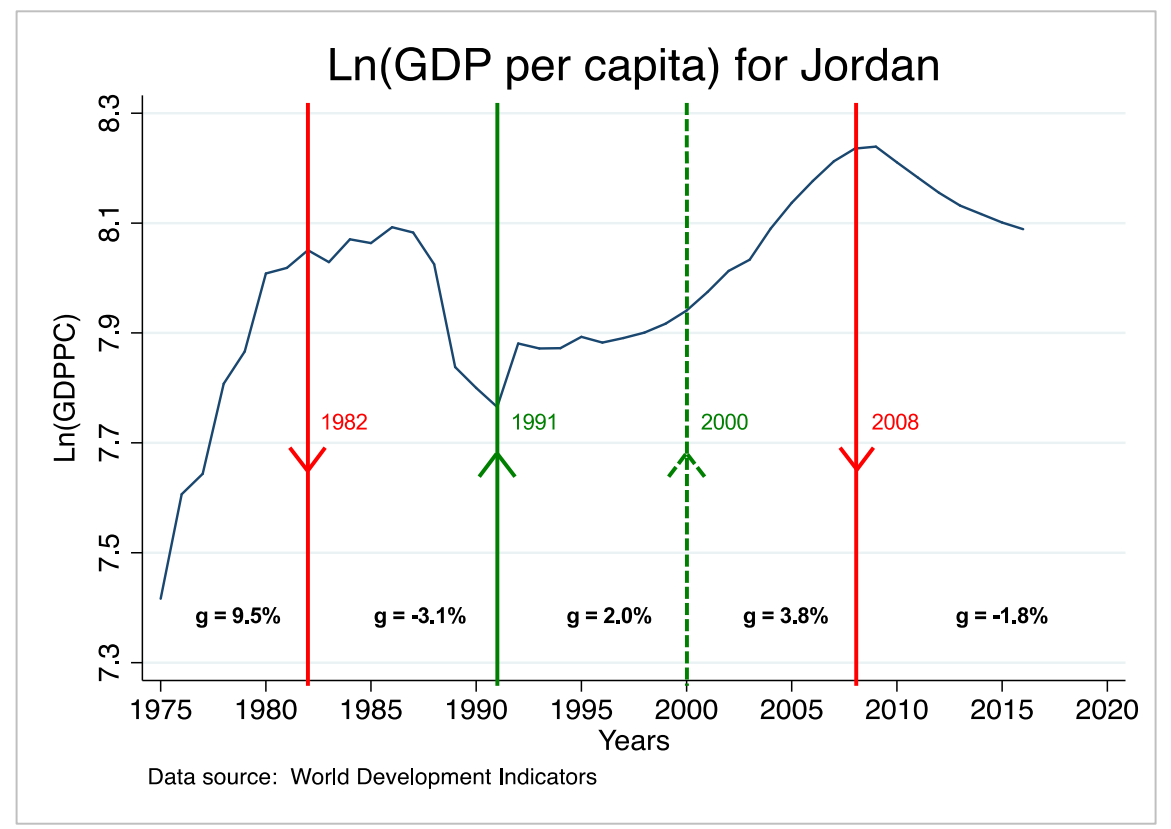

A comparison of Jordan's growth performance against other middle-income countries of the Middle East and North African (MENA) region reveals that the country's economic boom was larger than elsewhere prior to the structural break (2008), whereas the ensuing deceleration was relatively similar to its counterparts'. ${ }^{2}$ However, when viewed in per capita terms - as illustrated in Figure 2 - Jordan's (and to a lesser extent, Lebanon's) contraction grossly outpaces the region's, due to the massive influx of refugees driven by the

\footnotetext{
${ }^{1}$ In identifying structural breaks in Jordan, we have relied on a combination of Kar, Pritchett, Raihan and Sen (2013) and Wald (1943), applied over growth series data from World Development Indicators (WDI) 1975-2017.

${ }^{2}$ Comparators here include other middle-income MENA countries, excluding Syria, Iraq, Yemen, Libya, and Palestine.
} 
Arab Spring (2011) and by the Syrian refugee crisis (2014). According to World Bank figures ${ }^{3}$ Jordan's population grew from 6.5 million in 2008 to 9.9 million at the close of 2018 . Failure to cope with a $52.6 \%$ increase in population between 2008 and 2018 - a trend that was particularly exacerbated after 2014 by the Syrian refugee crisis - has caused Jordan to register nine consecutive years of negative growth rates in GDP per capita, resulting in a cumulative loss of $14.0 \%$ over the past decade.

Figure 2. GDP Growth and GDP per capita (selected countries)
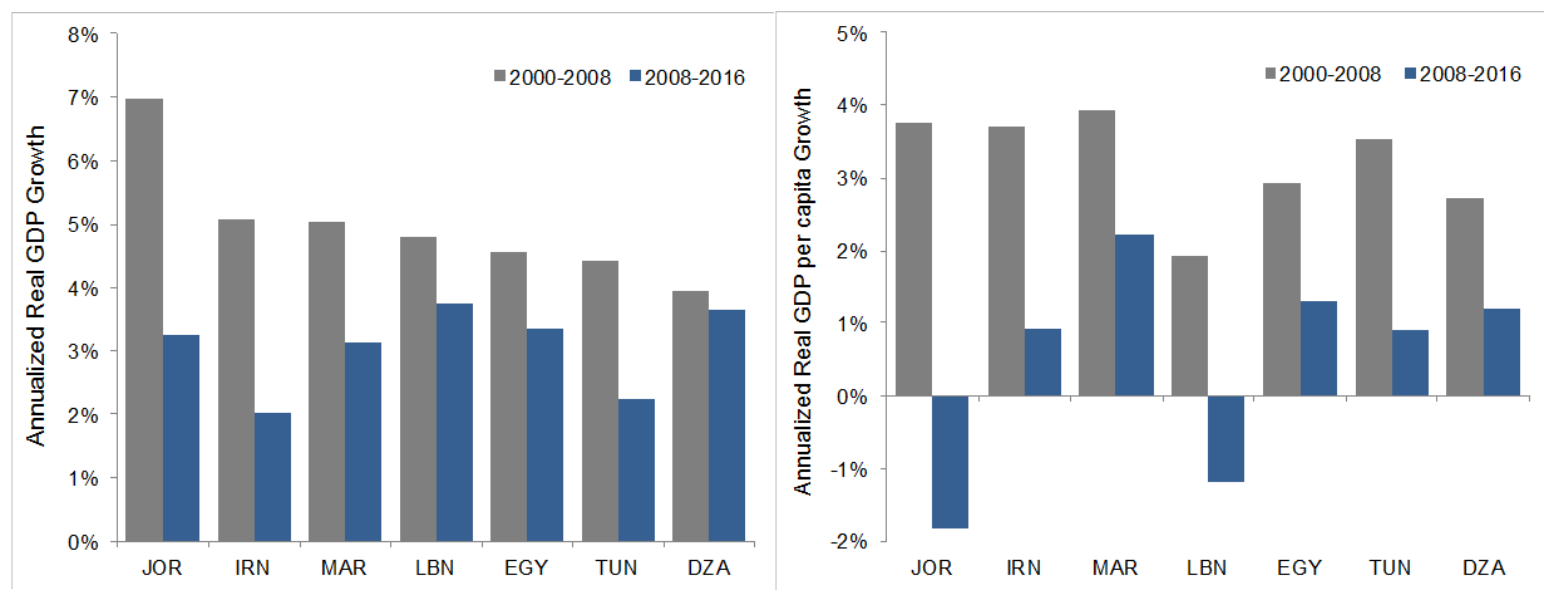

Source: World Development Indicators, World Bank.

The contribution to growth of different sectors (Figure 3) reveals substantial differences between the economic boom and the deceleration period. In the former (2000-2008), growth was driven by a significant increase in manufacturing (1.74 percentage points, or pp); finance, insurance and real estate (1.54 pp); and transportation, storage and communications (1.00 pp). Together, these three sectors accounted for two-thirds of the average annual growth (6.9\%) recorded between 2000-2008. From then onwards, within the context of a significant deceleration (compounded annual growth rate - CAGR - of 2.8\% between 2008 and 2017), the contribution of the manufacturing sector fell to one-sixth of what it had been in the previous decade $(0.3 \mathrm{pp})$, while the service sector - including financial, real estate and insurance ( 0.79 pp.), transport, storage and communications ( 0.49 pp.), and wholesale and retail $(0.26 \mathrm{pp}$.) - took the lead in driving growth.

\footnotetext{
3 We have used the World Development Indicators from the World Bank for the period 1960-2017 (https://data.worldbank.org/country/jordan, consulted in on February $1^{\text {st }}$ 2019). For 2018 we have relied on the population figures projected in the World Economic Outlook of the IMF for Jordan: 2.1\% population growth in 2018.
} 
Figure 3. Contribution to GDP growth by sector (percentage points) ${ }^{4}$

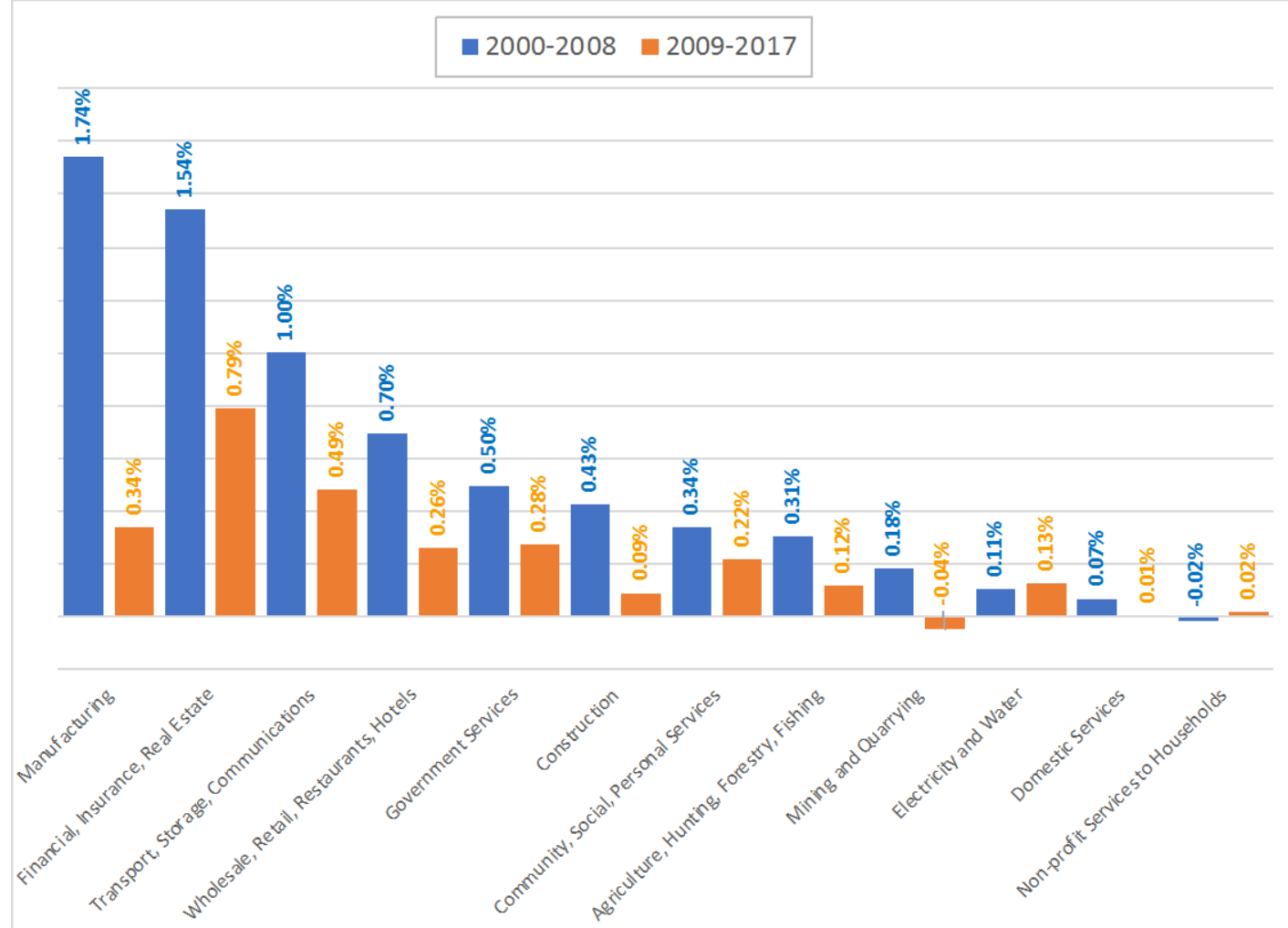

Source: Central Bank of Jordan.

\section{External shocks: Impacts on exports and foreign direct investment}

Jordan's growth trajectory from 2009 to 2018 has been negatively affected by various external shocks that had significant impacts on the country's balance of payments. The global financial crisis (2008-2009), the Arab Spring (2011), the Syrian civil war (2011), and the Daesh conflict in Iraq (2014), decelerated trade and investment flows at a global level, and in the case of Jordan, sparked a series of events that led to the closure of borders with key export markets, a massive inflow of refugees, and a disruption of the energy supply due to sabotage. The adverse effects stemming from these events impacted Jordan's balance of payments by curtailing two key sources of foreign currency: exports and foreign direct investment.

\footnotetext{
${ }^{4}$ Contribution to growth is calculated as the compounded annual growth rate (CAGR) of the sector over each period, multiplied by the average weight of the sector within gross domestic product.
}

9|Jordan: The Elements of a Growth Strategy 


\subsection{Exports}

The extent to which these external shocks affected Jordan cannot be overstated: both the economic boom and the ensuing slowdown were export-driven (Figure 4). From 2000 to 2008, Jordan's exports grew by a factor of 3.6, expanding at a CAGR of $17.3 \%$ per annum $(14.1 \%$ in constant dollars). This went beyond a mere commodity boom: it entailed significant gains in market share for Jordan's exports, in particular, for garments, chemicals, and agricultural goods. From 2008 to 2017, the more challenging external conditions and less dynamic market-share gains slowed down export growth to a CAGR of $1.3 \%(-0.2 \%$ in constant dollars). Over this period, export performance can be broken down into two clearly differentiated sub-periods. Between 2008 and 2014 , export growth decelerated (3.4\% per year, $1.8 \%$ in constant dollars), as global trade slowed down and Jordan's market share gains in garment and chemical exports stagnated. After 2014, the intensification of armed conflicts in the region and the interruption of important trade routes caused exports to plummet by a cumulative $8.2 \%$ ( $11.5 \%$ in constant dollars). The downturn was particularly sharp in agriculture, transport and tourism.

Figure 4. Jordan: Exports of goods and services

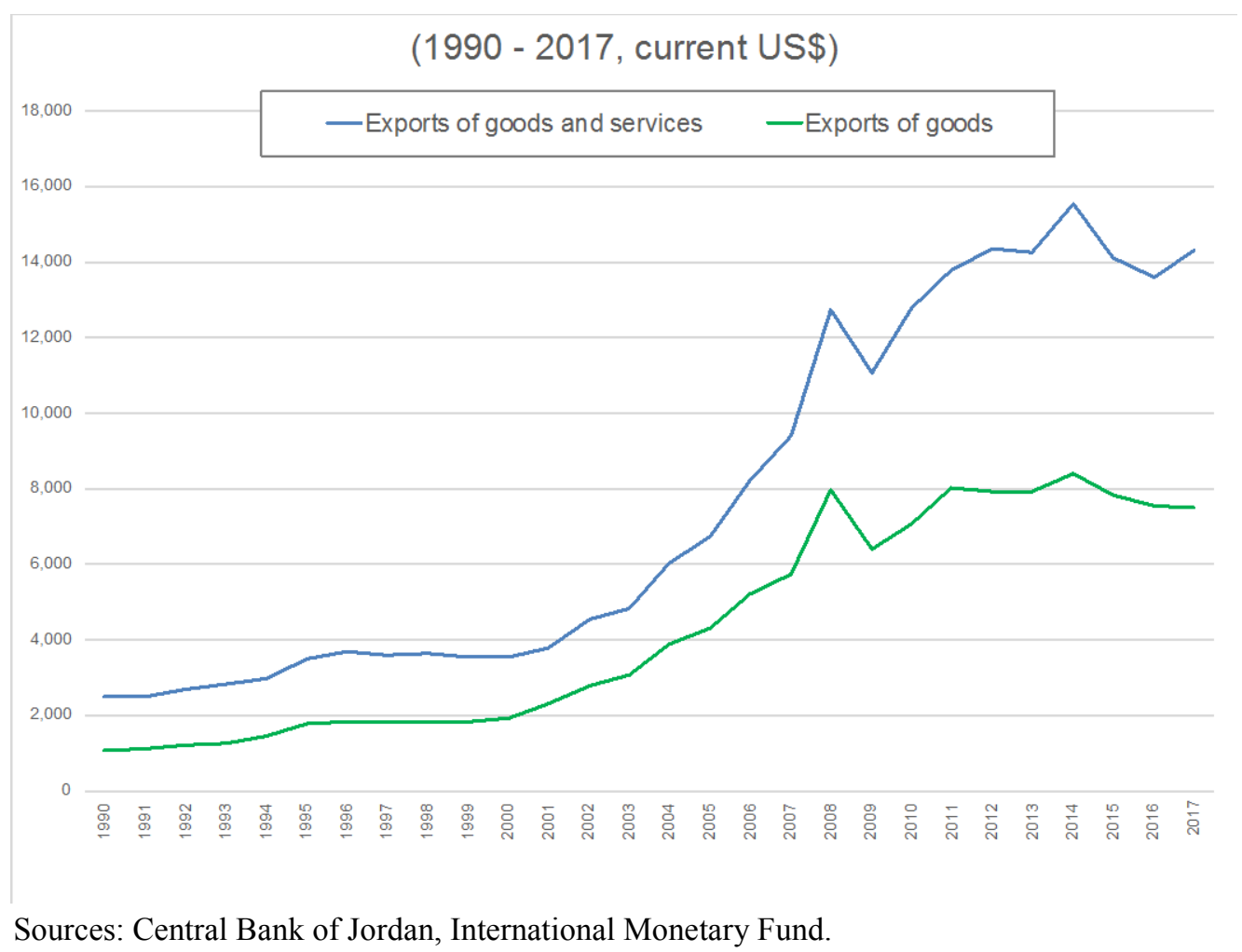

10 |Jordan: The Elements of a Growth Strategy 
The 2014 sharp fall in exports caught everyone by surprise. By the end of 2017, total exports of goods ${ }^{5}$ were 20\% lower than the IMF Article IV 2014 forecast; and 33\% below the Article IV 2012 forecast. These gaps are quite significant, as they represent $4.7 \%$ and $9.5 \%-$ respectively - of Jordan's 2017 GDP.

\subsection{Foreign Direct Investment}

Another negative impact derived from the global financial crisis and the regional instability sparked by the Arab Spring was the substantial slowdown in foreign direct investment (FDI). Throughout the years of expansion, Jordan had been running large current account deficits that were mostly financed by massive inflows of FDI: Foreign investment over the 2003-2009 period averaged US $\$ 2.1$ billion - $12.9 \%$ of GDP - fueled by countries benefiting from the prolonged oil bonanza (Figure 5). The United Arab Emirates (UAE), Bahrain, Saudi Arabia and Kuwait, accounted for $50 \%$ of all FDI received by Jordan during this period. After the global financial crisis - from 2010 to 2017 - FDI flows fell to an average of US \$1.7 billion, or 5.0\% of GDP. New partners such as Malaysia, South Korea and Egypt came in to compensate for receding investment still flowing from UAE, India, the United States, Bahrain and Kuwait.

Figure 5. Foreign Direct Investment (2003-2017)

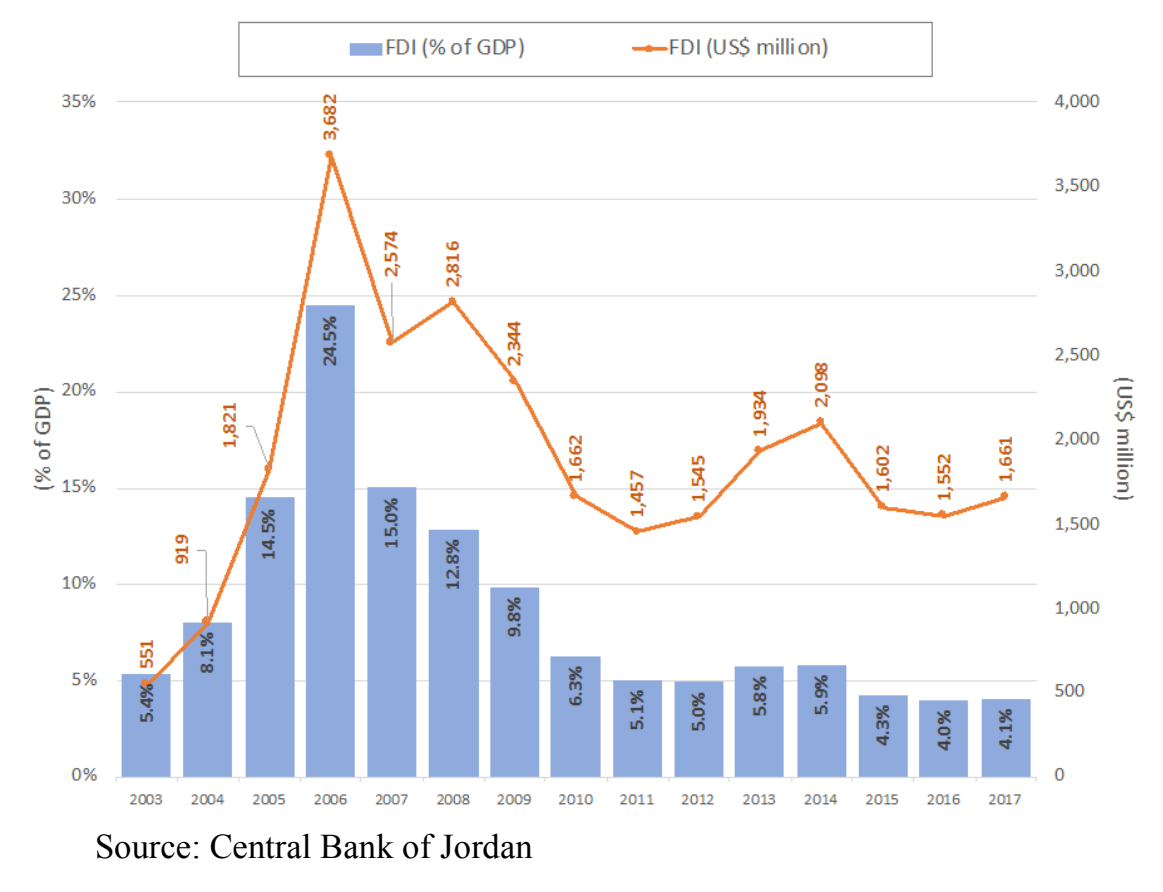

\footnotetext{
${ }^{5}$ Here, we use exports of goods as a reference, as the 2012, 2014, and 2017 IMF Article IV reports do not forecast service exports in an individual category, but rather in net terms.
}

11 |Jordan: The Elements of a Growth Strategy 
Changes in patterns of FDI flows occurred not only with regards to volume and country of origin, but also in terms of industry. FDI in construction and manufacturing - which accounted for $73 \%$ of all FDI received by Jordan between $2003-2009$ - fell by $63 \%$ and $38 \%$ respectively between 2009-2016. By contrast, the energy sector attracted US $\$ 4.4$ billion - 38\% of total FDI received between 2010-2016. The information, communications and technology (ICT) sector attracted an additional US \$530 million during the aforementioned period.

\section{Jordan's macroeconomic and fiscal outlook}

As a consequence of the harsher economic conditions, Jordanian imports suffered a very significant decline. Between 2014 and 2017, total imports fell by 10\% (Figure 6), which in real per capita terms represents a 20\% drop below 2014 levels, and a 44\% decline from their 2008 peak.

Figure 6. Exports and imports of goods and services

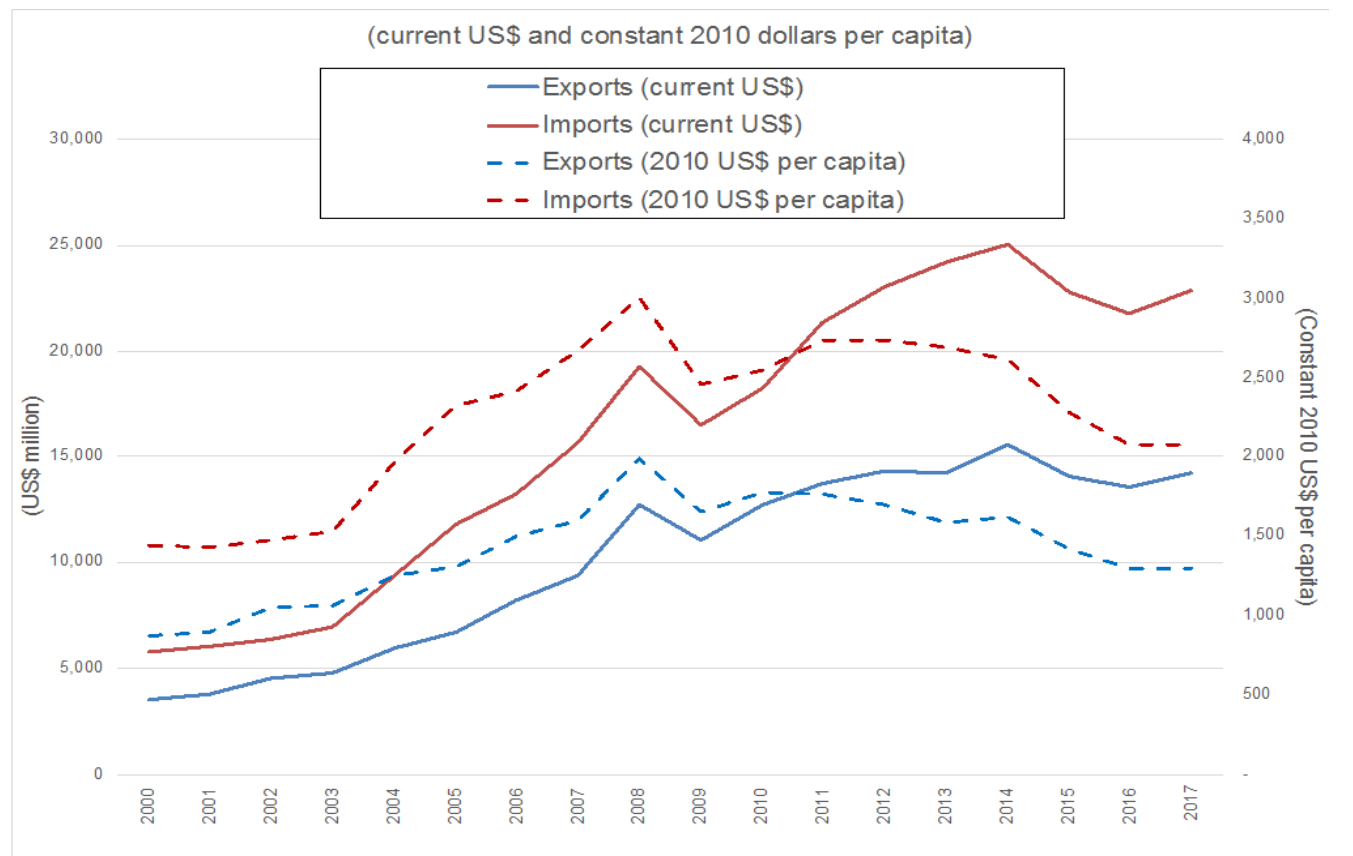

Source: Central Bank of Jordan

In spite of the substantial decline in imports, the current account deficit remained large (Figure 7). More importantly, while the deficit was predominantly financed through FDI until 2012, public external debt has played a much bigger role from 2012 onwards. 
Figure 7. Current Account Deficit, FDI, and Foreign Public Debt

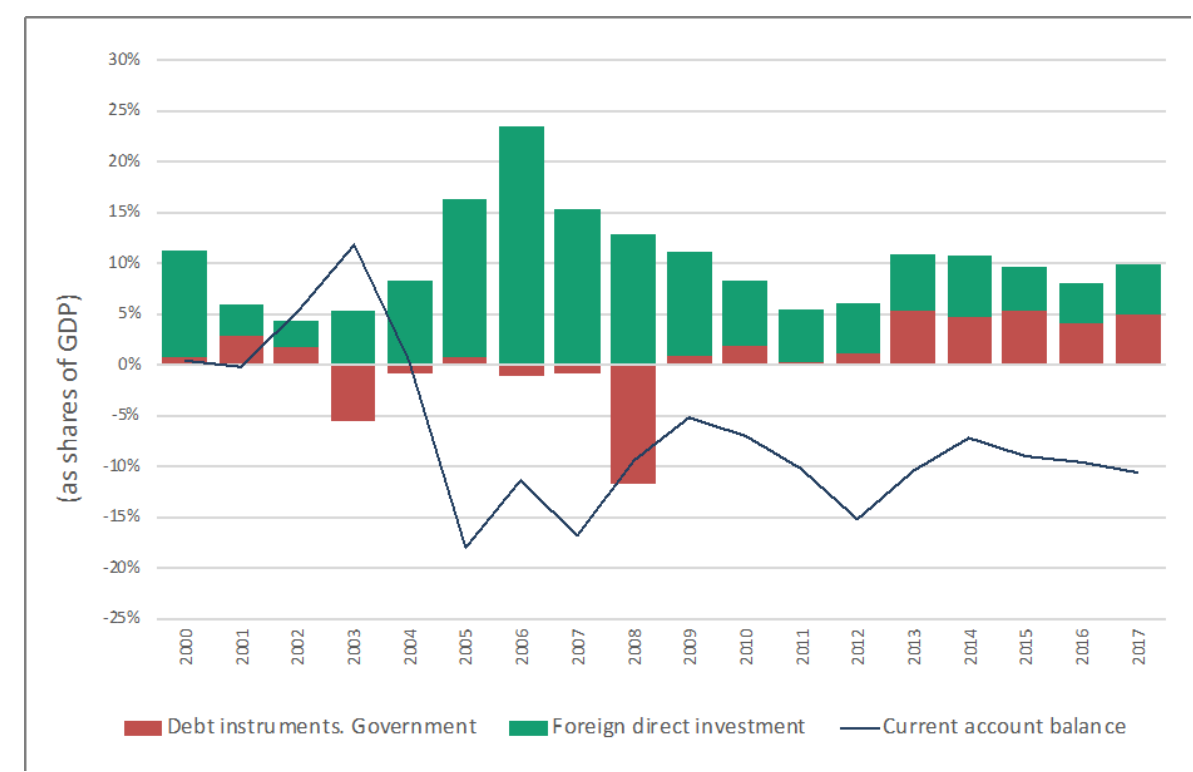

Source: Central Bank of Jordan

The external shocks, the lower level of growth and imports, compounded with the security challenges in the region and the costs associated with the Syrian refugee crisis, all put Jordan's fiscal accounts under severe strain.

During the global financial crisis, Jordan's fiscal accounts took a big hit. Between 2007 and 2011, tax revenues declined by a whopping 9.4\% of GDP. The government responded with a large expenditure cut of $4.6 \%$ of GDP. As a consequence, the fiscal deficit - excluding grantsgrew by $4.8 \%$ (from $7.9 \%$ to $12.7 \%$ of GDP) (Figure 8 ). When grants are factored in, the increase was much more moderate, totaling $1.7 \%$ of GDP (from $5.1 \%$ to $6.8 \%$ of GDP). ${ }^{6}$

After 2011, Jordan's continued and massive fiscal adjustment cut the deficit (excluding grants) by a staggering 7.6 percentage points, bringing it down to $5.1 \%$ of GDP by the end of 2017 (2.6\% of GDP including grants). The colossal fiscal adjustment was carried through higher indirect taxes (2.9\% of GDP), decreased subsidies on goods (3.5\% of GDP), and capital expenditures (1.4\% of GDP). Jordan's fiscal adjustment is one of the largest recorded in the world since the global financial crisis, ranking third only behind Jamaica (2009-2015; 8.5\% of GDP) and Greece (2010-2016; 10.7\%), but well ahead of Portugal (2010-2016; 6.1\%) and Spain (2009-2015; 4.6\%).

${ }^{6}$ The deficit we are referring to here is the Budgetary Central Government (BCG), which includes 25 ministries, the Prime Ministry, Parliament, and 28 departments contained in the General Budget Law. It does not include the deficit of public enterprises, an omission that is somewhat compensated by the fact that it does account for transfers to public enterprises. 
Figure 8. Jordan: Budgetary fiscal balance (2005-2017)

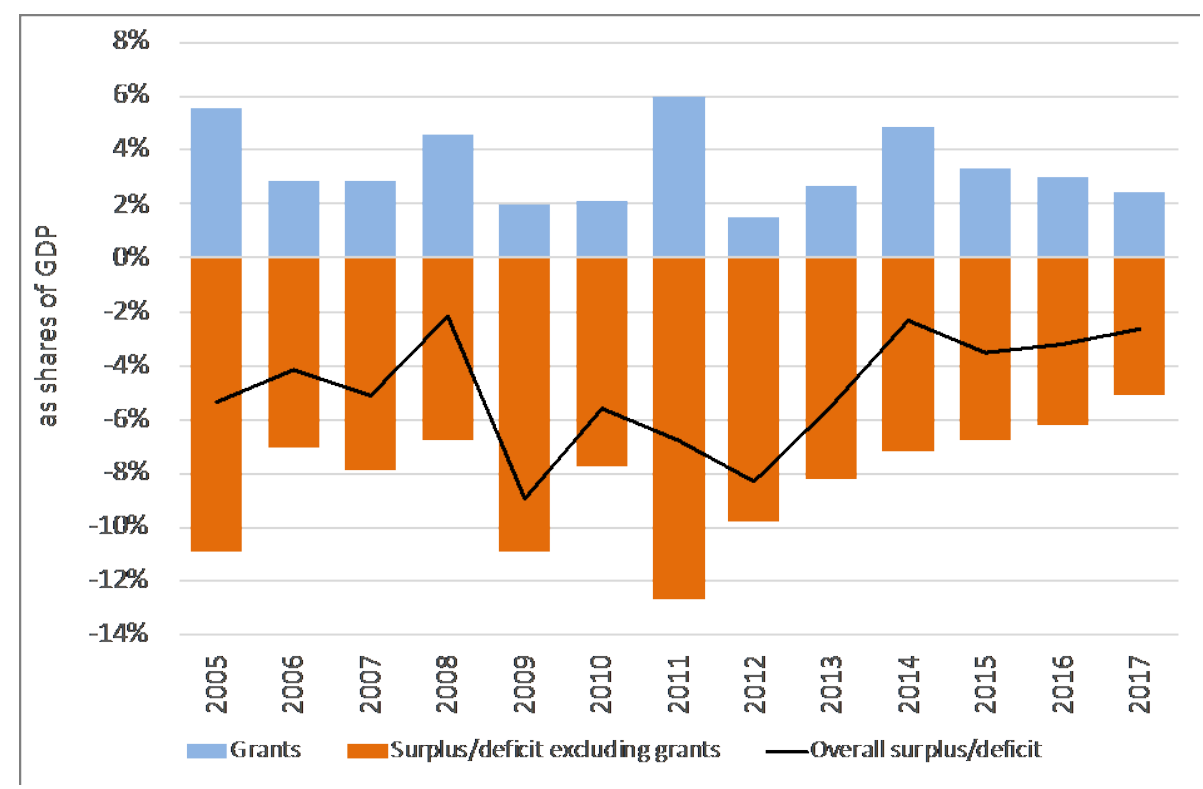

Source: Central Bank of Jordan

The Jordanian economy proved to be remarkably resilient, as it continued to grow albeit at a decelerating pace - in spite of the tremendous fiscal drag. Between 2011 and 2017, the fiscal impulse - defined as total fiscal expenditure excluding external debt payments, minus total fiscal revenues excluding grants - dropped by 8.1 percentage points of GDP. Countries that achieved comparable fiscal consolidations such as Jamaica, Greece, Spain and Portugal suffered deep recessions. Jordan, in turn, achieved positive growth.

Yet, in spite of impressive fiscal adjustment, the gross debt-to-GDP ratio rose from 55\% of GDP in 2009 to its current level of 94\% of GDP. In order to stabilize the debt-to-GDP ratio with a nominal GDP and a nominal interest rate of $6 \%$, ${ }^{7}$ the primary surplus would have to be $3.8 \%$. If the goal was to reduce the debt-to-GDP to $77 \%$ by 2025 , the primary surplus would have to be $5.7 \%$. However, in 2017 , the primary surplus was only $1.7 \%$.

Having said this, further fiscal adjustment is not the only way - nor is it sufficient- to lower the debt-to-GDP ratio. Table 1 presents the primary surplus required to bring the debt-toGDP ratio down to $77 \%$ by 2025 for different combinations of nominal growth rates and nominal interest rates. As the table shows, if the nominal growth rate could be accelerated to $6 \%$ (say $4 \%$ real growth and $2 \%$ inflation) and the interest rate kept to $6 \%$, the debt-to-GDP ratio could be

${ }^{7} \mathrm{On} \quad$ February 11, 2019, A 5-year bond was yielding 5.96\% according to http://www.worldgovernmentbonds.com/country/jordan/, consulted on February $11^{\text {th }}$. 
brought down to $77 \%$ with a primary surplus smaller than the one achieved in 2017 . A similar primary surplus would be needed if the nominal growth rate was only $5 \%$, but the interest rate were lowered to $4 \%$. The implications are clear: the debt-to-GDP ratio can be put on a solid downward path if current levels of primary surplus are maintained or improved, if growth is accelerated, or if financing is made available on softer terms.

Table 1. Primary fiscal surplus, growth and yields needed to achieve 77\% of Debt-to-GDP by 2025

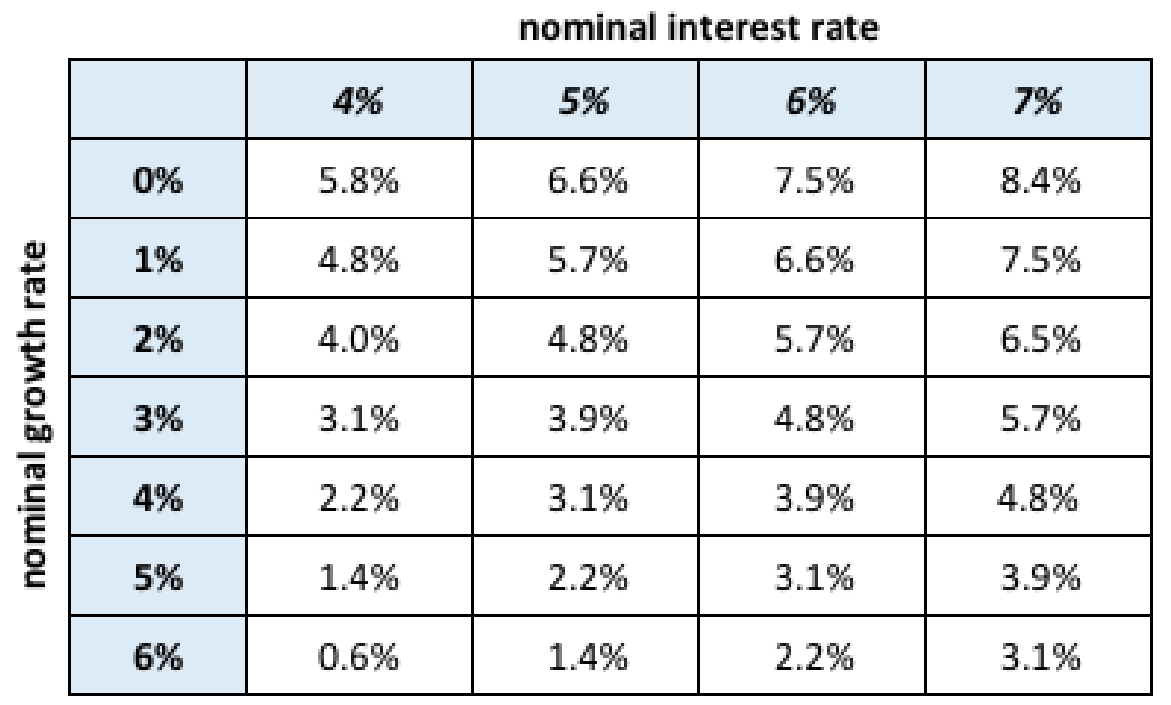

Source: Authors' own calculations based on Central Bank of Jordan and Minister of Finance data.

Two important propositions can be derived from this analysis. First, that fiscal consolidation alone will most likely be insufficient to achieve debt sustainability in a reasonable timeframe. At current growth and interest rates, debt sustainability would require further fiscal drag, which would inevitably inhibit growth. Instead, the country could achieve fiscal consolidation if fiscal discipline is accompanied by a more aggressive growth strategy, complemented by an international financial strategy aimed at reducing the average cost of its debt.

The second implication is that, given the need for continued fiscal discipline and the already large current account deficit, the growth strategy cannot depend on fiscal stimulus and domestic demand, but should instead be led by exports and by investments that directly or indirectly increase exports. Within such a context, considerations of comparative advantages become crucial. 


\section{An export-led growth strategy: comparative advantage considerations}

\subsection{High-cost electricity}

A significant portion of the net increase in debt registered in Jordan since $\mathbf{2 0 0 8}$ has to do with the 2011 disruption in the supply of Egyptian natural gas to the energy sector during the Arab Spring. The disruption forced Jordan's public electricity company NEPCO to substitute natural gas with diesel and heavy fuel oil at a time when oil prices were very high. The impacts can be observed in Figure 9: The costs of generating electrical power more than doubled between 2011 and 2014, opening a significant gap in NEPCO's revenues and costs.

The Jordanian government reacted by increasing average electricity tariffs - significantly raising them on most industries while keeping them relatively constant for the vast majority of households. ${ }^{8}$ Aggressive actions were also taken to move to cheaper sources of energy by developing the infrastructure needed to import liquefied natural gas (LNG). The government also held public tenders for solar and wind generation contracts, and entered into a series of long-term power purchase agreements (PPAs) aimed at achieving energy security.

Figure 9. NEPCO Costs and Revenues

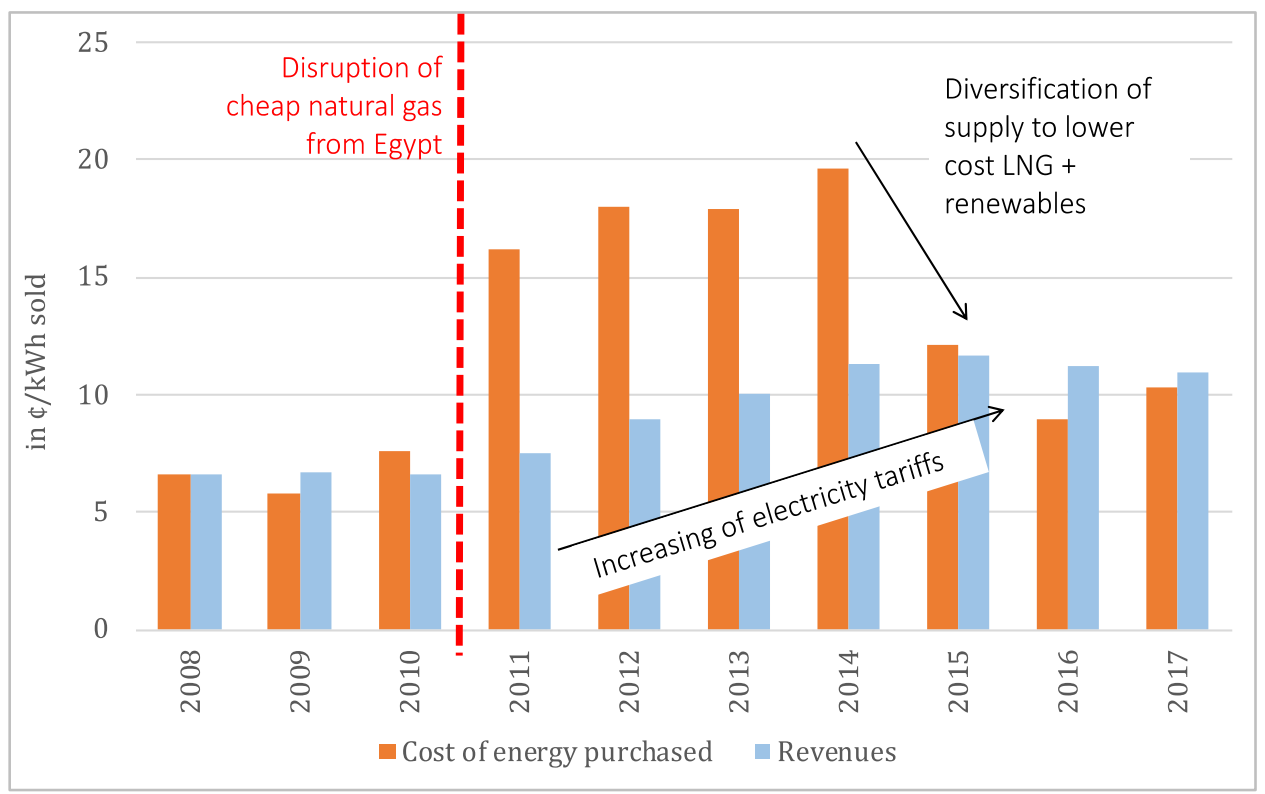

Source: NEPCO and Minister of Energy and Mineral Resources.

\footnotetext{
8 By 2017, the electricity bill of 55\% of Jordanian households fell into the lowest of four tariff brackets, which has experienced a cumulative increase of 3.1\% over the past ten years (2008-2018). Another 38\% of Jordanian households fell into the second-to-last tariff bracket, that experienced a cumulative $2.1 \%$ tariff adjustment over the same period.
} 
By 2015 the balance between NEPCO revenues and generation costs had been restored, but the country did not emerge unscathed from the 2011-2014 crisis. The gaps in NEPCO's profits and losses over those four years resulted in US \$7.3 billion worth of debt, which continues to loom over the system today. To make matters worse, the way in which the tariff adjustments were implemented left a highly dispersed and cross-subsidized tariff structure. Whereas before the crisis, the ratio between the highest and lowest electricity tariff was 2.7 , at present, the ratio is 8.0 (Figure 10).

Figure 10. Electricity Tariffs (2008-2018)

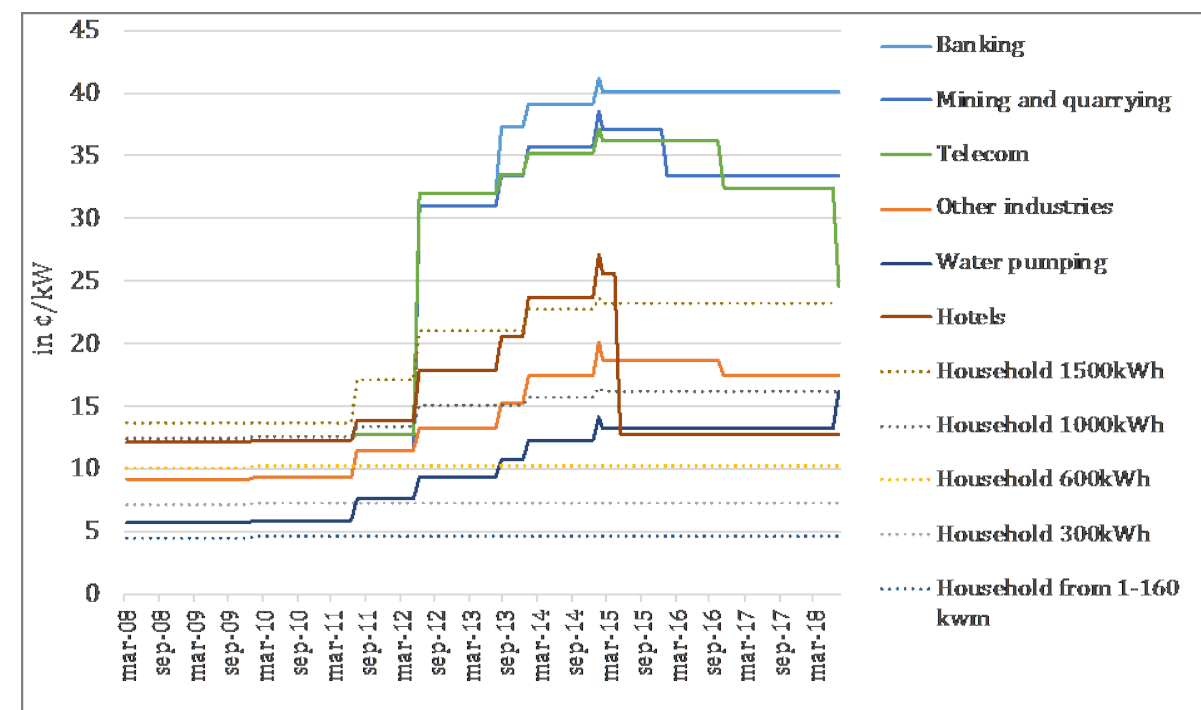

Source: NEPCO and Minister of Energy and Mineral Resources.

The long-term PPA contracts signed by Jordan, compounded with the large cross-subsidies embedded in the tariff structure, have made electricity costs become a binding constraint to growth and productive diversification in Jordan. Most industries saw their electricity costs double - and in several cases triple or quadruple. - over a decade. Electricity costs have become a threat to the competitiveness of both existing firms and potential tradable industries, constraining private investment, job creation, wage growth, and the overall resilience of the economy to cope with external shocks. Figure 11 presents a comparison of non-residential electricity tariffs that Jordanian industries are facing, compared to those prevailing in the Unites States of America at a state level, and some selected European countries. The Jordanian banking sector - to cite the most salient example- is paying tariffs that are four times higher than three quarters of the places sampled on the chart. More generally, all Jordanian industries are facing electricity costs that are several orders of magnitude higher than those prevailing elsewhere in the world. 
Figure 11. Electricity Tariffs by Industry (2008-2018)

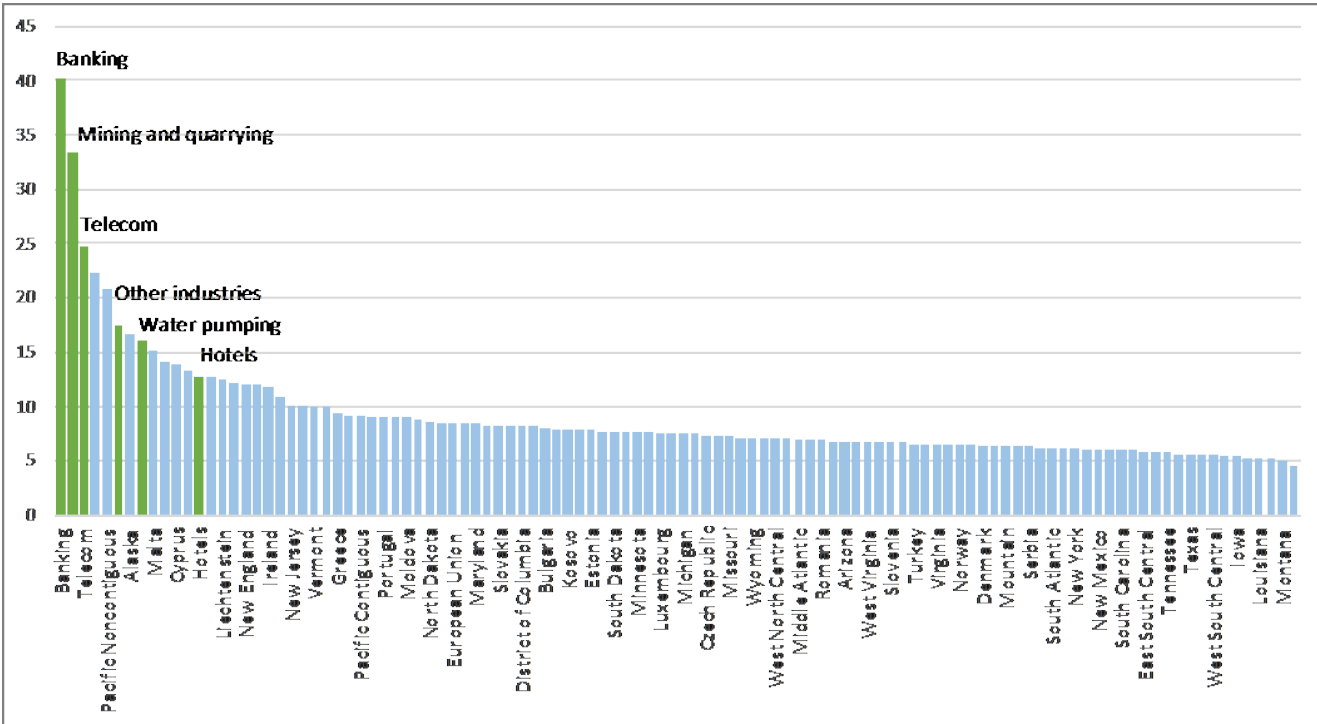

Source: NEPCO and Minister of Energy and Mineral Resources.

The spike in electricity generation costs had a significant negative impact on Jordan's manufactures, which, as a consequence of access to cheap gas, had evolved to be relatively energyintensive (Figure 12). Thus, it is unsurprising that the collapse in growth was concurrent with the the collapse in manufacturing - the period when electricity tariffs were rising sharply.

Figure 12. Share of Manufacturing Value Added by Energy Intensity (2010)

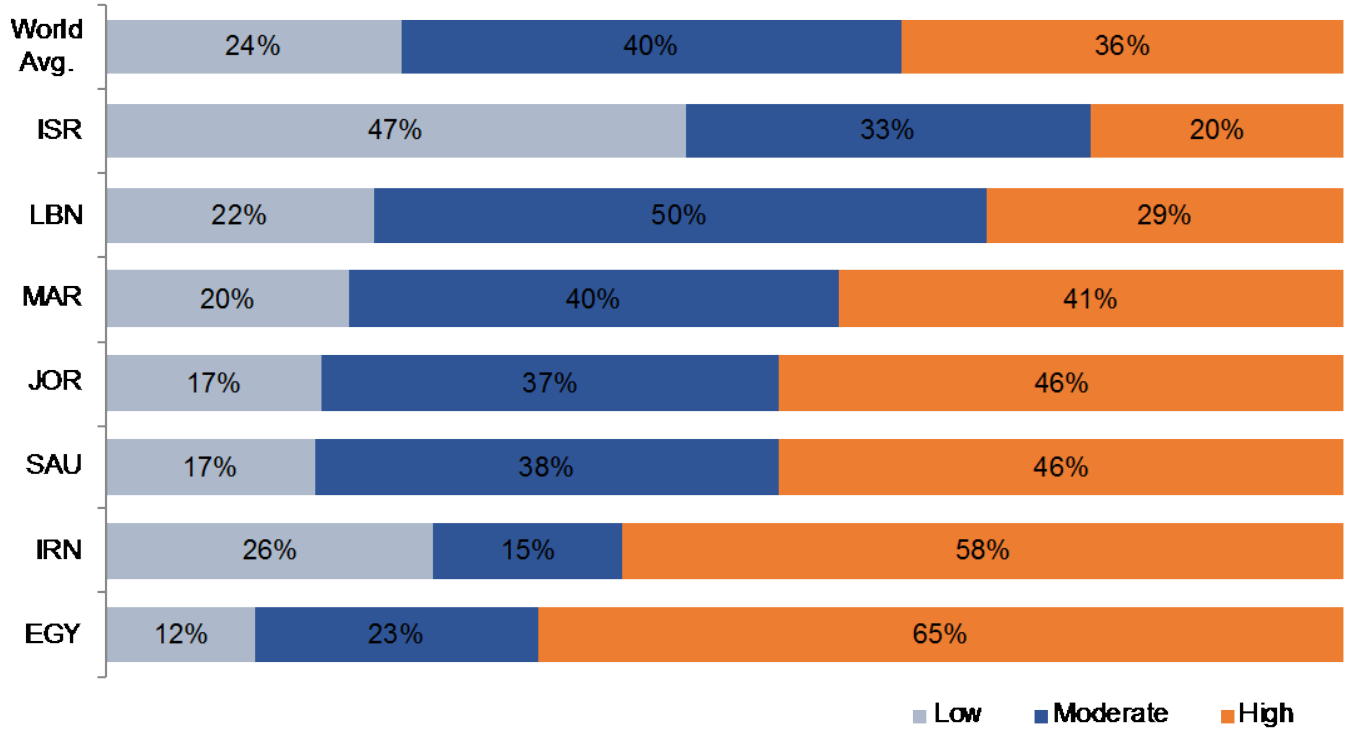

Source: UNIDO (2010)

18|Jordan: The Elements of a Growth Strategy 
The implications for Jordan's growth strategy in terms of energy are clear: In the near term, Jordan must focus on promoting exports and investments on industries that support exports that are not intensive in the use of electricity. In the medium term, a new energy strategy must be developed, aimed at lowering electricity generation costs by unlocking the potential of renewable energy -and in particular-solar, one of the country's strongest comparative advantages. Lower energy costs will not only improve the competitiveness of Jordan's industries, but also reduce balance of payments pressures (by reducing the imports of fuel oil and natural gas) and have strong, positive impacts on energy security (as conflicts in the region cannot alter solar radiation or the speed of wind).

At present, solar and wind provide intermittent electricity, but storage technologies are rapidly improving. Jordan's energy strategy must allow the country to benefit from the cost savings derived from future technological advancements. This would require an update of the PPA agreements so that they can fulfill their complementary, flexible role within Jordan's optimal energy mix.

\subsection{The odd and changing character of factor endowment: Human Capital}

Jordan has the unusual characteristic of being a net importer of low-skilled labor and a net exporter of high-skilled workers. This is not only due to the predominant role of foreigners in low-skill, non-tradable activities such as construction or domestic service; low-skilled foreign workers also play a very large role in some of the most important export activities such as such as agriculture, light manufactures and tourism (Figure 13). 
Figure 13. Jordan Labor Force by Industry

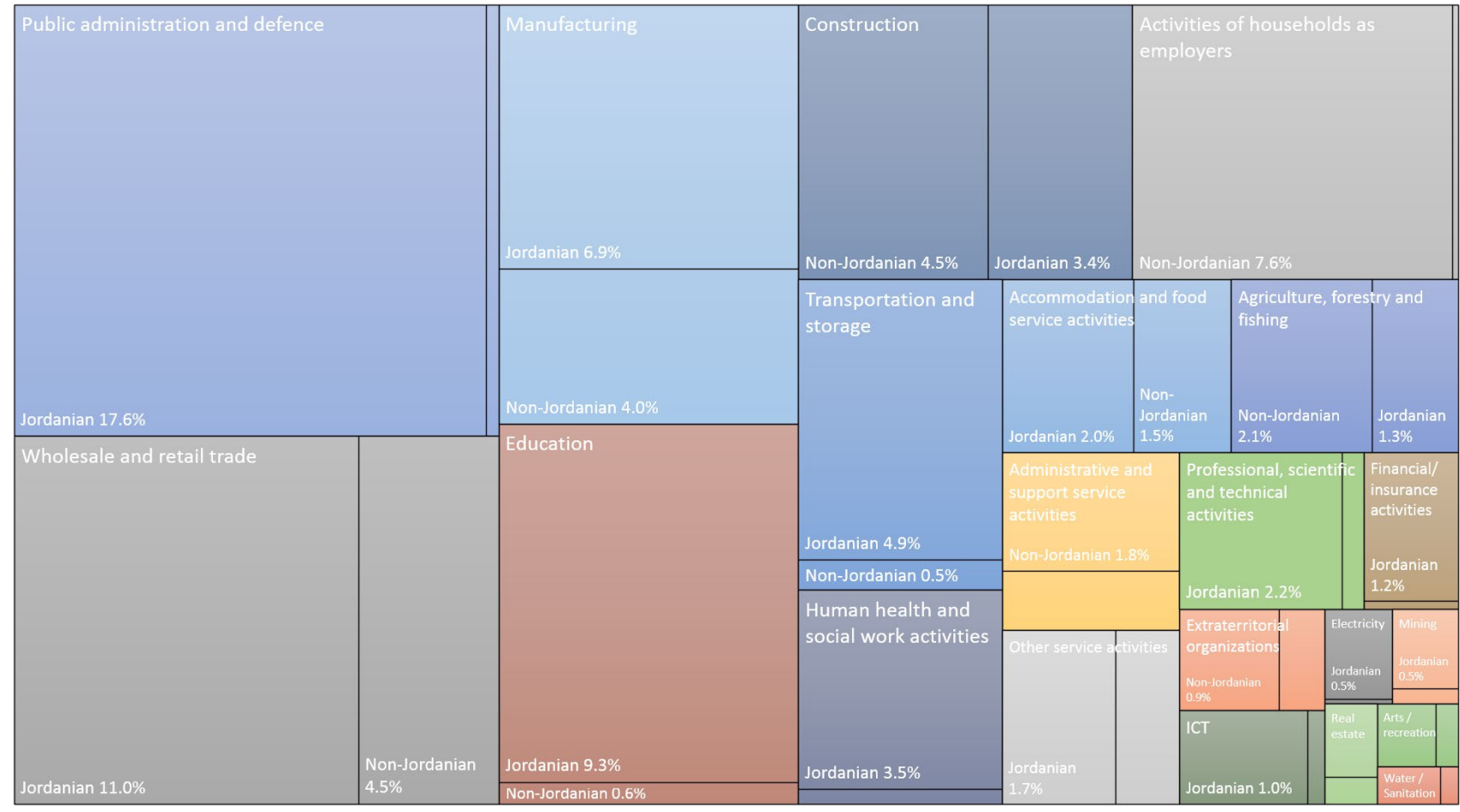

Source: 2017 Employment and Unemployment Survey

By the same token, many high-skilled Jordanians tend to migrate to other countries for work while those who stay behind face very high unemployment rates. This suggests that the country's export basket does not take advantage of the high-skilled human capital endowment that the country has built up.

This situation has an important gender dimension to it. By international standards, participation rates are low in Jordan across the board, but they are particularly low for lowskilled women. While more than $58 \%$ of men with less than complete high-school education participates in the labor force, only $5.5 \%$ of women with the same education level are employed or seeking employment. By contrast, men and women with post-graduate degrees participate at similar rates of around $73 \%$ (Figure 14). 
Figure 14. Labor Force Participation by Gender and Schooling

\section{Women's Labor Force Participation Rates in 2017}

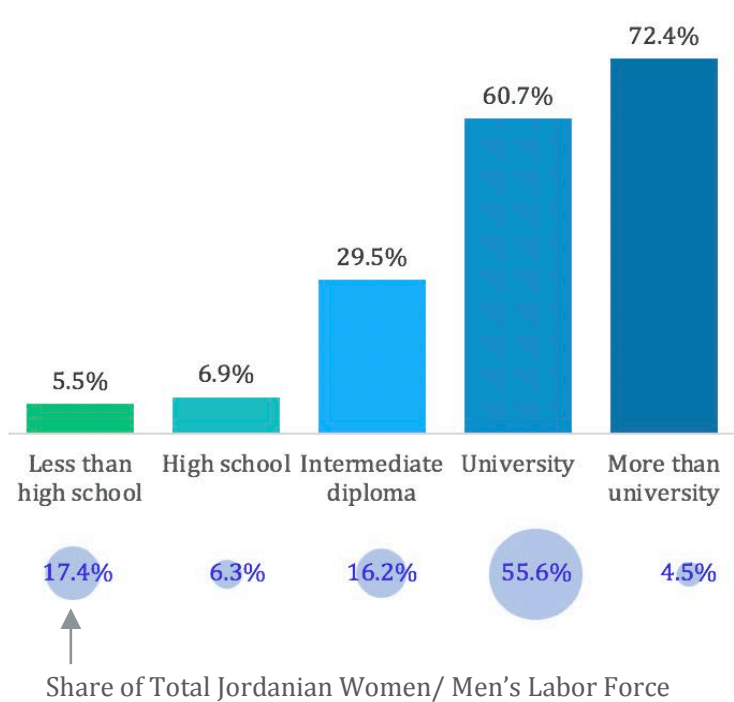

Source: 2017 Employment and Unemployment Survey

\section{Men's Labor Force Participation Rates in 2017}

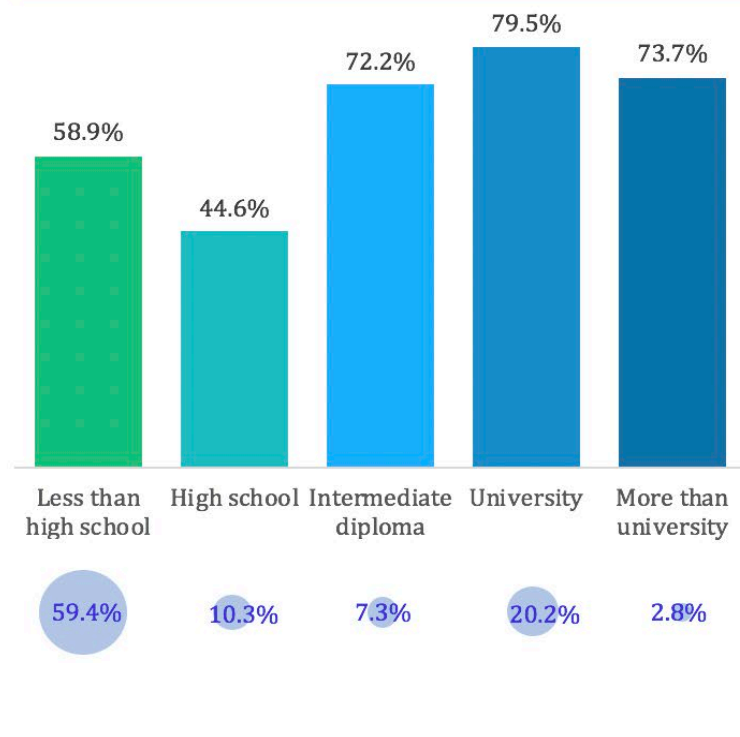

This means that - while women in Jordan are on average slightly more educated than men - the composition of the female labor force is dramatically more skilled than the men's, mainly because less educated women participate so little. So, whereas only $23 \%$ of men in the labor force have a university degree or higher, the rate for women is $60 \%$. But this supply of female labor is largely wasted, as high-skilled women face unemployment rates that are between two and three times higher than those faced by men with equivalent education levels (Figure 15).

Figure 15. Unemployment by level of education for Jordanian men and women

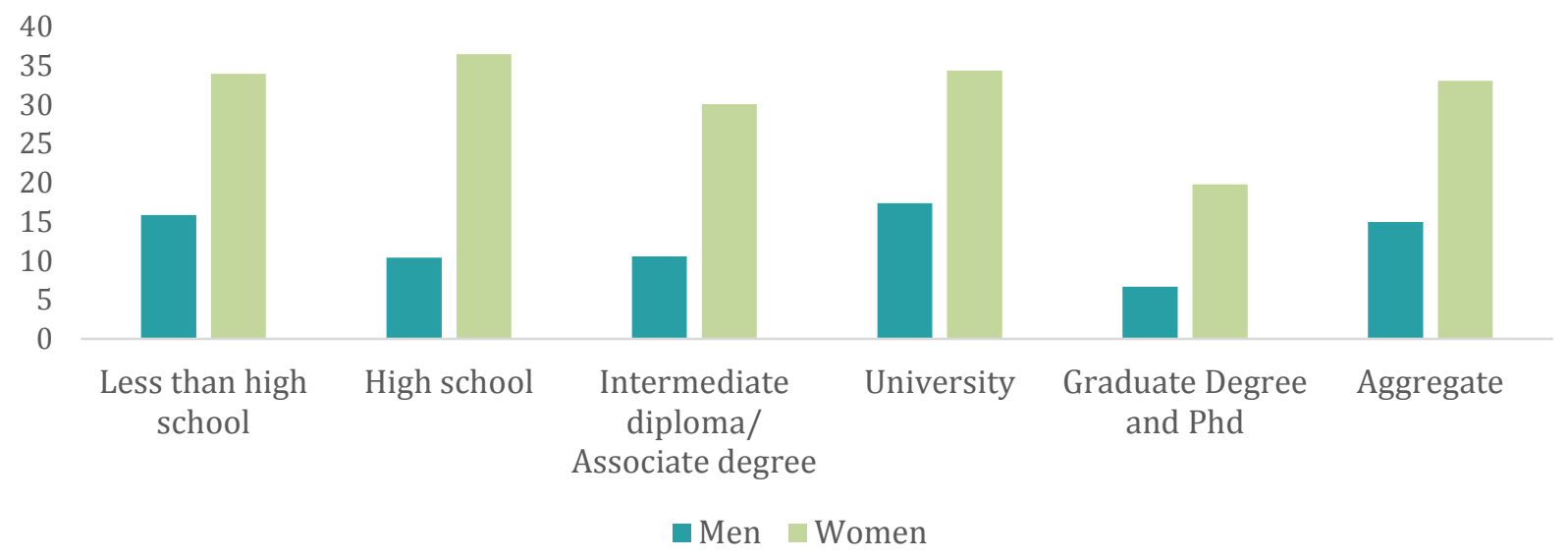

Source: 2017 Employment Unemployment Survey

21 |Jordan: The Elements of a Growth Strategy 
This situation is related to the fact that Jordanian women participating in the labor force have been largely restricted to a specific set of occupations in mostly high-skill industries. At present, education, healthcare, and public administration represent $30 \%$ of total employment but hire $68 \%$ of all employed Jordanian women and $81 \%$ of women with a post-graduate degree. The high concentration of employment in these three sectors suggests that these industries provide what are considered to be traditional female jobs.

While other economies are not exempt from having patterns of proportionally high female employment in certain industries, women nonetheless tend to sort into a more diverse set of fields in other countries, a process that is still nascent in Jordan. In the United States, for example, $78 \%$ of healthcare and social assistance and $68 \%$ of education services employees are women. Yet $57 \%$ of legal services and $56 \%$ of finance and insurance employees are also women.

A possible explanation for the very high rate of female unemployment is that a disproportionate number of Jordanian women compete, or are queuing for, the same few, desirable or traditional female jobs mentioned above. This queueing hypothesis is further supported by the unusually long duration of unemployment for Jordanian women. Long-term unemployment (more than one year) affects $72 \%$ of unemployed Jordanian women, compared to $58 \%$ of Jordanian men. Low participation of women in the workforce is therefore a direct result of not enough jobs being available, and not, as could be surmised, because of unusually high wage expectations: the selfreported median reservation wage for unemployed women was 300 JOD in 2016, while median wages of employed Jordanian women was 350 JOD. ${ }^{9}$

Moreover, the education, health services and public administration sectors have not grown fast enough to hire the pipeline of women who finish university degrees. In the coming years, these three sectors could not possibly grow at a sufficient rate so as to provide more than a small fraction of the jobs that educated Jordanian women will be looking for. If we conservatively assume that tertiary enrollment and labor force participation rate by gender remain constant for the next ten years, the labor force will change massively towards high-skilled workers: from $28.1 \%$ in 2017 to $40.5 \%$ in 2027 . The share of men in the labor force with university degrees will climb from $20.2 \%$ to $30.3 \%$ but the share of women will increase from $56.7 \%$ to $68.3 \%$. The total number of women with university degrees will increase by $85.7 \%$ and that of men by $77.2 \%$. There is no conceivable scenario in which education, healthcare and public service will hire more than a fraction of these women. Between 2010 and 2016, education and healthcare added about 3,000 female jobs a year. In the coming decade, we expect an increase in the supply of women with

\footnotetext{
${ }^{9}$ Idem.
} 
university education of 16,000 per year. Unless the country changes its areas of comparative advantage to reflect the growing endowment of educated and increasingly female workers, the accumulated human capital will be wasted (Figure 16).

Figure 16. Structure of labor force (actual and forecasted)
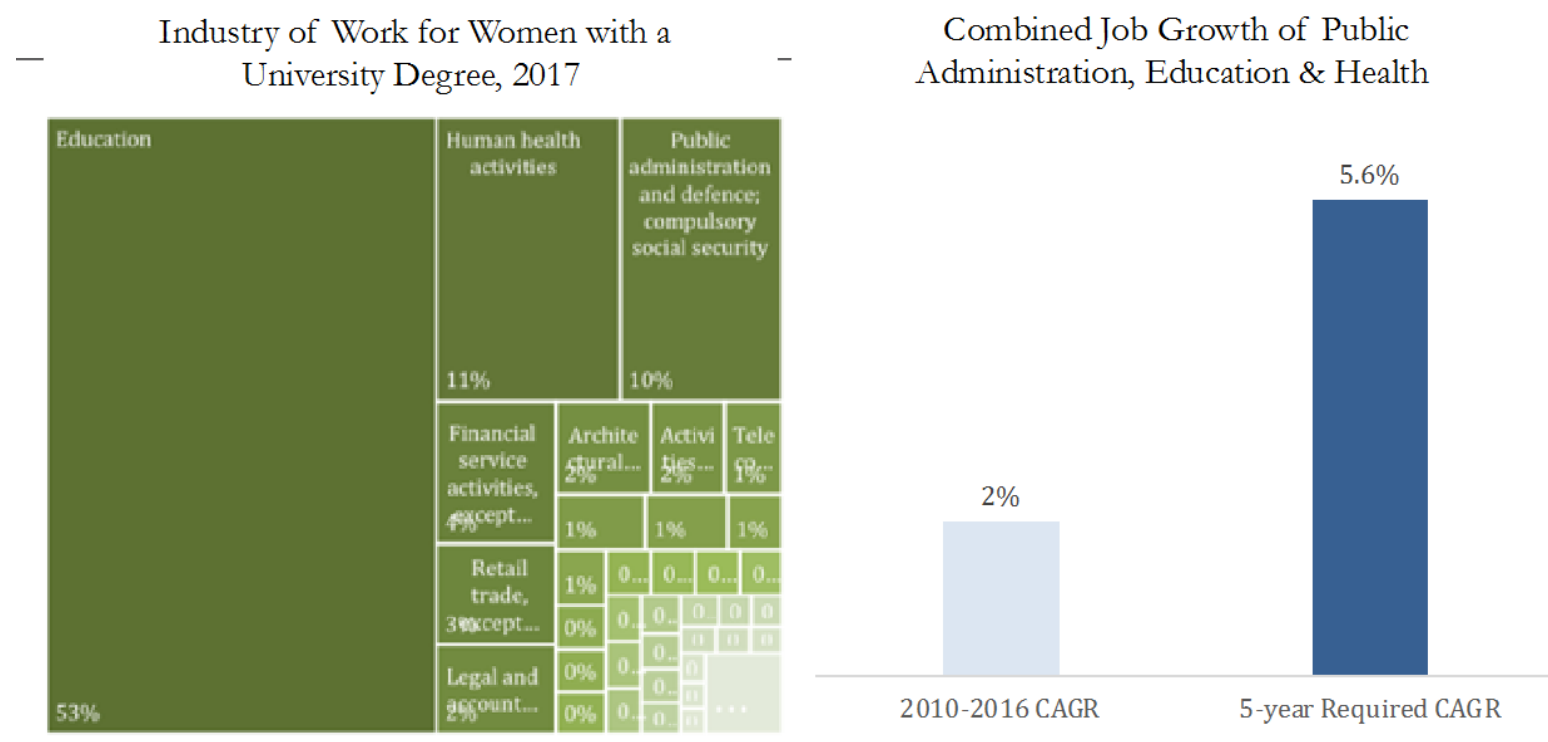

Jordan's growth strategy needs to pay special attention to high-skill export activities that can hire more women. Figure 17 provides an indication of which sectors could include such activities. The figure shows employment of each industry group in Jordan along two dimensions: the share of jobs in the sector filled by Jordanians versus non-Jordanians (on the horizontal axis), and the proportion held by women (in the vertical axis). Industry groups are shown as circles that are sized according to their total employment. Red circles show that an industry group pays a median wage that is below the national median wage, while blue circles shows a median wage above the national median. It is clear from the figure that industry groups in the upper left corner are strategic for creating more job opportunities for high-skilled Jordanian women. These industry groups include not just education and healthcare, but finance and insurance, professional, scientific and technical activities, and information and telecommunications.

This is a first indication that tradable service sectors should be an area of focus, because they are intensive in a factor of production that is already in excess supply and will be increasingly so in the coming years. 
Figure 17. Jordanian labor market (2017)

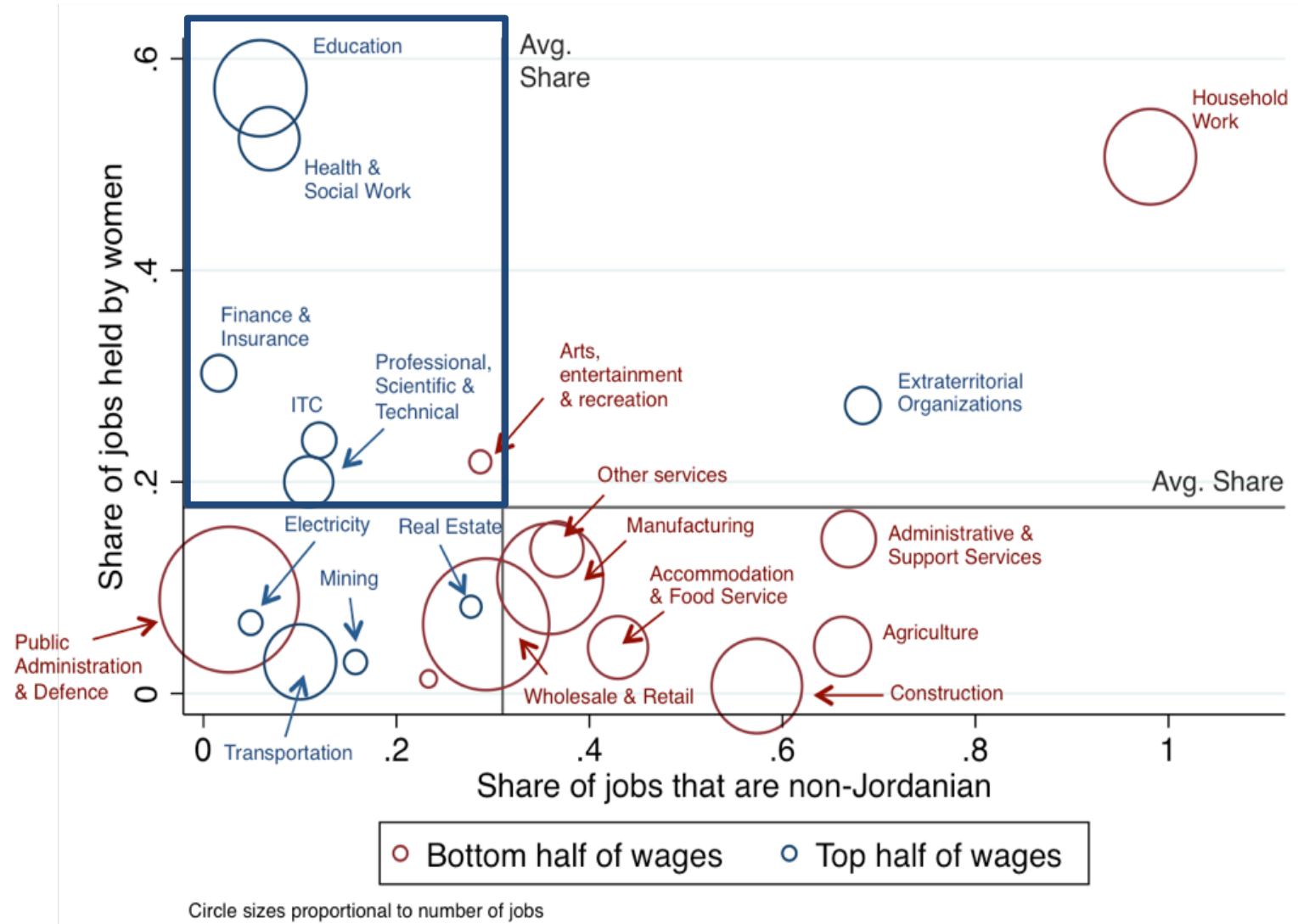

Source: Employment and Unemployment Survey, 2017

\subsection{Complementary high-skilled immigration}

One significant reason why the Jordanian economy does not more closely reflect its factor endowment of human capital is self-imposed by the country's immigration policy. Jordan's immigration system has historically been very liberal for low-skilled workers, while being very restrictive for high-skilled labor. This starves the economy of specific skills and experience that could be secured from the global labor market which would complement the skills and training of highly educated Jordanians. Econometric evidence and firm interviews provide strong suggestive evidence that this policy constraint is suppressing growth of high-skill, tradable services in Jordan that would otherwise be poised to grow.

Over the long-term, Jordan's immigration policy has implicitly treated all foreign workers as if they are substitutes - assuming that one more job filled by a foreigner means one less job 
for a Jordanian - instead of recognizing the critical role that complements play in the Jordanian economy. This policy focus is especially evident within Jordan's list of closed professions to foreigners, last updated in 2016. However, in the presence of labor complementarities - when one job filled by a foreigner with a specific skillset in short supply in Jordan allows for the creation of several Jordanian jobs - this policy focus can become a significant constraint on growth. This is, in fact, the reality that labor market evidence in Jordan makes clear. In effect, Jordan's immigration policy is meant to achieve both national security and economic security, but by restricting access to the foreign workers that are complements, it is actually causing economic insecurity.

The presence of complementarities in key sectors that are tradable; that support high wages; and that employ higher-than-average rates of college graduates and women can be exemplified by the experience of a few specific companies, while the prevalence of the trend can be understood through econometric tests. To understand the nature of complementarities, take the example of the global software company, Expedia, and its operations in Jordan. Expedia opened a software development branch in Jordan in 2017 and, by the middle of 2018, employed around 100 high-skilled Jordanian software engineers, around half of whom were female. However, in order to put these skilled Jordanians to work, Expedia reported that they struggled to hire two foreign workers with global experience in Expedia's business model that they could not supply in Jordan due to immigration policy restrictions. This constraint was overcome in the case of Expedia, allowing the company to create approximately 50 local jobs for every high-skilled foreigner that it brought into the country, but it is unknown how many similar investment opportunities fall through because companies choose other countries in which to invest where they do not face the delays and transaction costs that the Jordanian system creates. A similar scale of complementarities of high-skilled foreign workers was found across other companies providing high-skill, tradable services that CID interviewed in Jordan.

Econometric tests using microdata from the 2017 Employment and Unemployment Survey confirm that this pattern is widespread in the Jordanian economy. Figure 18 shows the wage premium of foreign workers in Jordan versus their Jordanian counterparts (controlling for education and potential years of experience) in four of Jordan's largest sectors by employment. The survey data for these large sectors of the economy show that foreigners in most low-skill occupation categories - including "elementary workers," "craft and related trade workers," and "services and sales" workers - receive a negative wage premium versus their Jordanian counterparts. In other words, these foreigners are paid less and tend to be substitutes. However, there is a large and statistically significant positive wage premium among the occupation category of "professionals." The point estimates range from around $10 \%$ more in wholesale and retail trade to $35 \%$ more in manufacturing, suggesting strong complementarities. 
Figure 18. Wage Differences of Foreigners versus Jordanians in Four Large Sectors
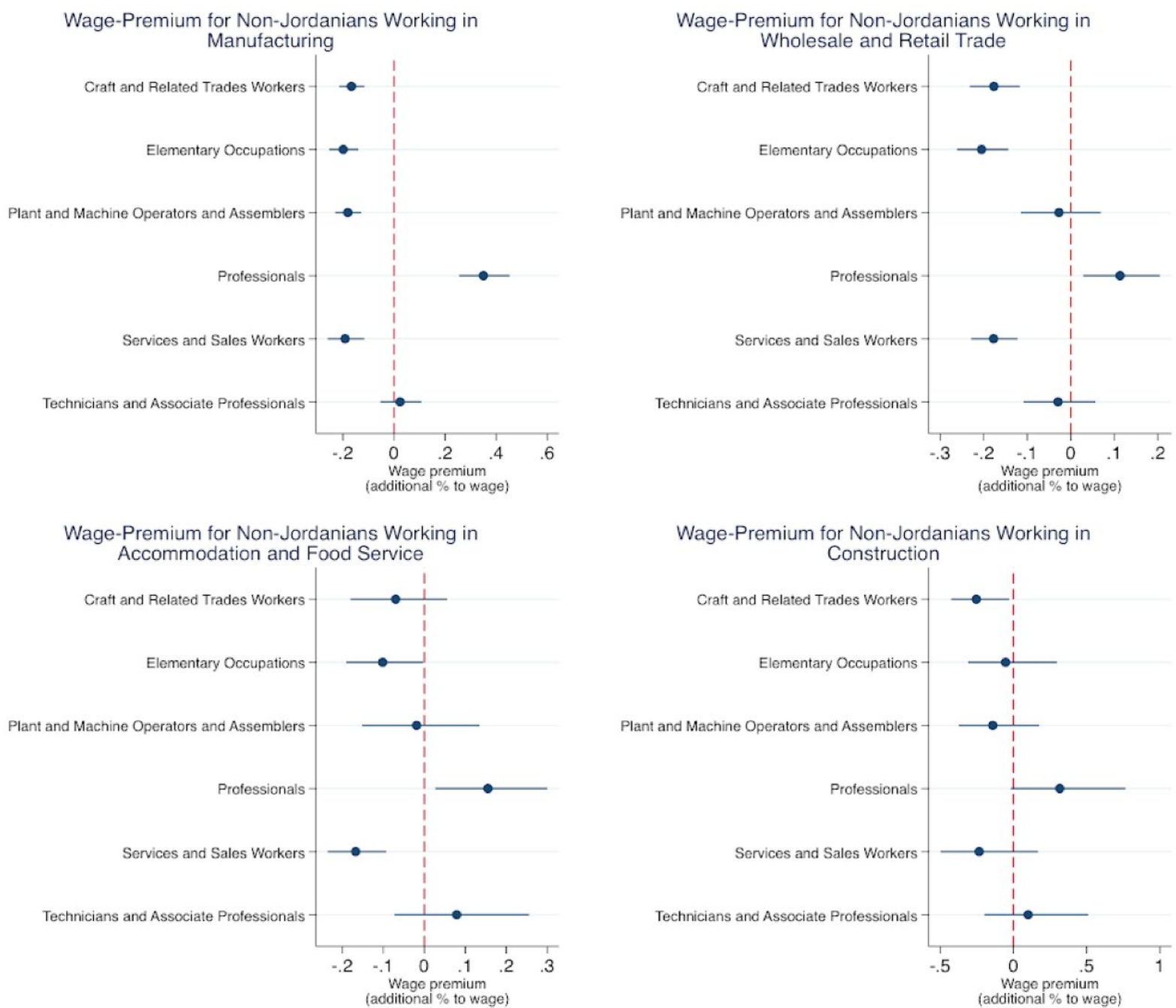

Note: Wage premia are calculated through a Mincer regression that controls for education, experience, gender and occupation fixed effects. Estimate and 95\% confidence interval are shown.

Source: CID calculations based on 2017 Employment and Unemployment Survey

Though not usually thought of as high-skill on the whole, these four sectors of the economy - which are responsible for nearly half of private sector employment in Jordan depend on specific skills of foreign professionals to fulfill some key tasks. If companies were not able to hire these foreigners in several professional and technician positions, it would result in Jordanians losing jobs. When the analysis is duplicated for professionals in key high-skill sectors where wages and female employment rates are higher than average, the results (Figure 19) show 
high point estimates for the wage premia paid to foreigners, albeit with large statistical uncertainty. This is the result of immigration policy itself. Because foreign workers are restricted in many of these activities, very few foreigners appear in the annual survey. Because very few foreign workers are present, the ability of these sectors to expand and employ more high-skilled Jordanians, including women, is constrained. The consequence is high unemployment and high rates of emigration for skilled Jordanians.

Figure 19. Wage Differences of Foreigners vs. Jordanians in High-Wage Sectors

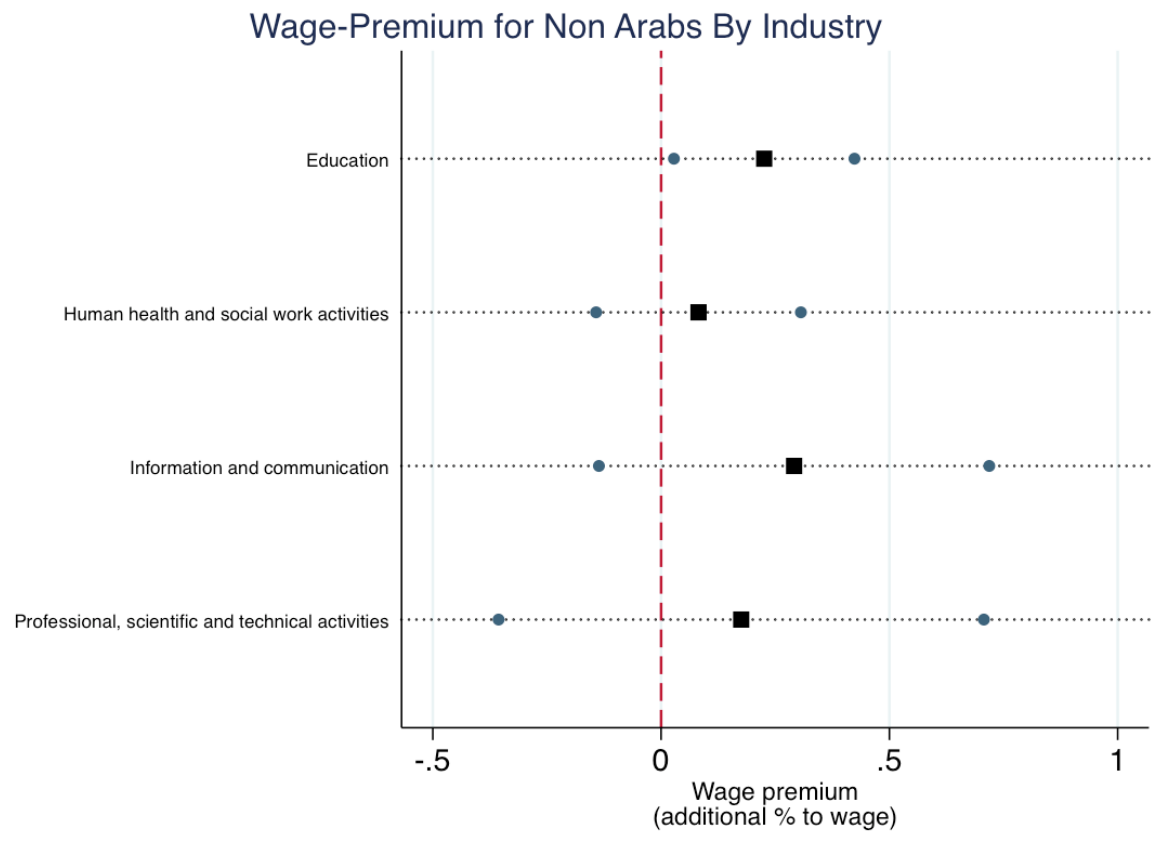

Note: Wage premia are calculated through a Mincer regression that controls for education, experience, gender and industry fixed effects. Estimate and $95 \%$ confidence interval are shown. Note: Insufficient sample for the Finance \& Insurance sector.

Source: CID calculations based on 2017 Employment and Unemployment Survey

An estimation of the wage premium paid to foreign professionals across all sectors of the economy and by nationality of origin (Figure 20) shows that complementary foreign professionals are coming from both Arab and Non-Arab countries, but the effect is especially strong for Non-Arabs. This mirrors the Expedia example: in order for companies from outside the Arab World to set up operations in Jordan, they will often need to bring some of their workers from outside the Arab World as well. While this logic may be straightforward, it runs against the logic of Jordan's 1996 Labor Code, which stresses that Arab "experts, technical specialists and workers" be given priority over other foreigners. 
Figure 20. Wage Differences of Professionals by Nationality

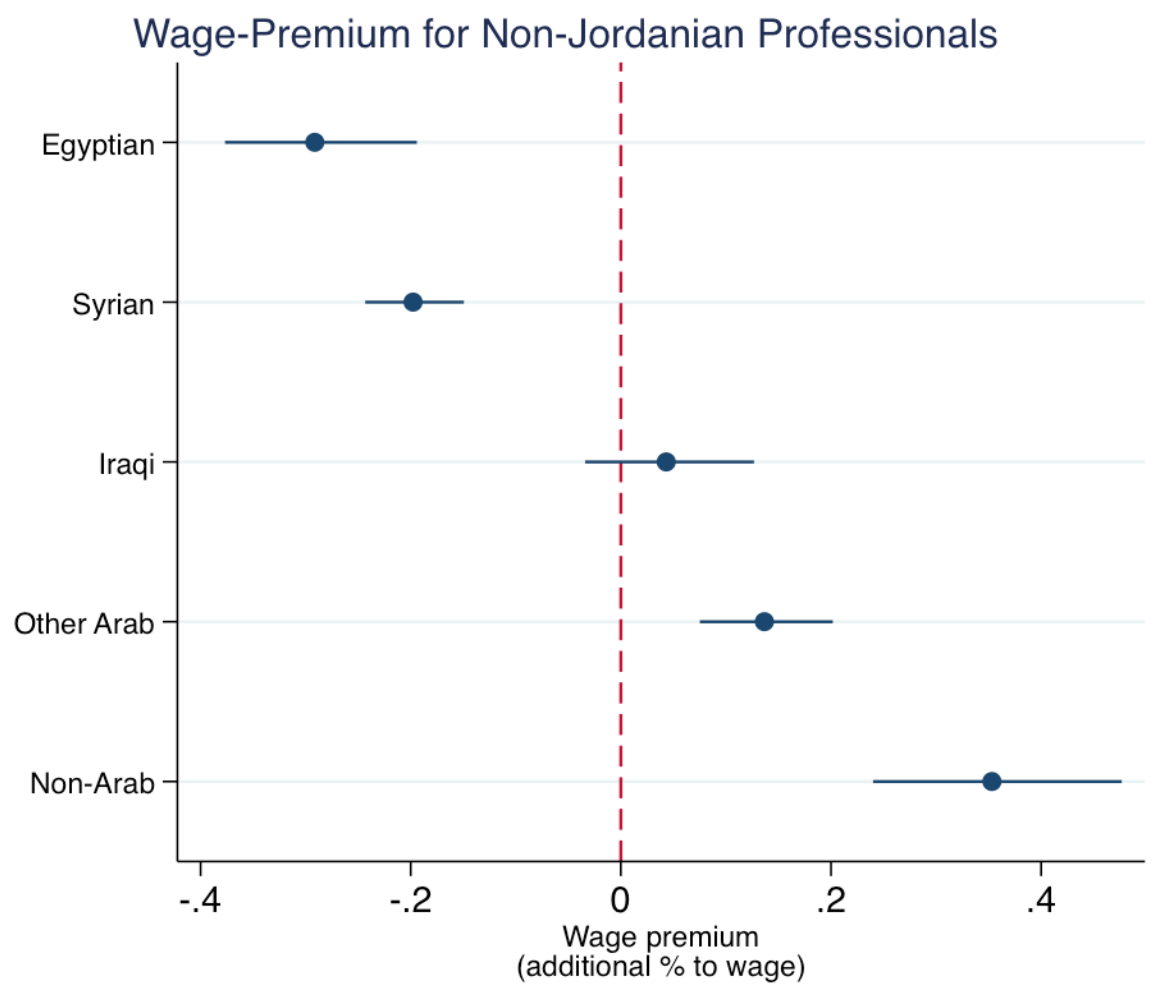

Note: Wage premia are calculated through a Mincer regression that controls for education, experience, gender and industry fixed effects. Estimate and 95\% confidence interval are shown. Source: CID calculations based on 2017 Employment and Unemployment Survey

One priority for a prosperous Jordan is therefore to resolve constraints to firms in accessing high-skilled and highly experienced foreign labor and to encourage entrepreneurs and businesses to set up operations in Jordan. Currently, critical restrictions apply to foreign workers in certain occupations and sectors as of 2016. The most glaring mismatch between the list of closed professions and the needs of the economy is engineering specialties, but the closed list includes several other categories tend include professionals: medical specialties, all of education, administrative duties, accountants, communications jobs, and the electricity sector. Although exceptions can reportedly be made through an individual review process through a panel at the Ministry of Labor, the reliance on this process is completely incompatible with the potential growth rate of high-skill, tradable sectors in which Jordan should have a comparative advantage. The majority of global companies are not willing to deal with the delays, uncertainty and, ultimately, the costs inherent in this system. They will simply choose another country in which to invest instead. This causes Jordan to lose out on jobs for Jordanians and for potential sources of export growth. 


\section{Understanding Economic Complexity inclusive of services}

For Jordan to grow its way out of the balance of payments constraint that its economy currently faces, it will need to maximize the growth potential from its greatest asset - its human capital - placing a special awareness on factors of production that are currently scarce and expensive. The theory of Economic Complexity - introduced by Hausmann, Hidalgo et al. (2011) - is based on the observation that structural transformation advances through the slow accumulation of productive capabilities and through learning-by-doing. One way to operationalize the concept is by using different measures of technological proximity between pairs of products, i.e. how similar the capabilities and skills required to manufacture one product are to those needed to manufacture another.

The central idea of this theory is that places reveal their stock of productive know-how through the goods and services they are able to produce successfully, and that future diversification of places tends to occur into products that are similar to those that they already produce. Over time, places with higher agglomeration of productive know-how will be able to manufacture a broader array of goods (more diversity) as well as goods that are increasingly difficult to make (higher complexity). By the same token, places with little agglomeration of knowhow, will only be able to produce a narrow set of goods of little technological sophistication, that on average, many other places are also able to make (high ubiquity). The basic tenets of Economic Complexity theory are expressed through indicators of economic complexity for places (economic complexity index, ECI) and for products (product complexity index, PCI).

Several studies into Jordan's diversification opportunities have been completed using the tools of Economic Complexity, including a two-part study by the Jordan Strategy Forum in 2017. These studies reveal that Jordan's ECI, as measured by its goods exports, has been falling over the last 20 years. This results in relatively few new diversification opportunities, and raises the question of what opportunities would emerge if services were included. 


\subsection{Incorporating goods and services: Dun and Bradstreet dataset}

Services are of great importance to Jordan. From 1995 to 2008, Jordanian service exports grew steadily from US $\$ 1.7$ billion to US $\$ 4.8$ billion. Despite the strong impacts of the 2008-2009 global financial crisis on the country's economy, service exports only experienced a minor hiccup during this period, and eventually grew to US \$7.1 billion in $2014 .{ }^{10}$ Service exports continued to expand from 2009 to 2014 when goods exports stagnated; by 2016, they accounted for nearly 45\% of total exports, which is relatively high when compared to benchmark countries (Figure 21).

Figure 21. Jordan: Exports by Category (1995-2016)

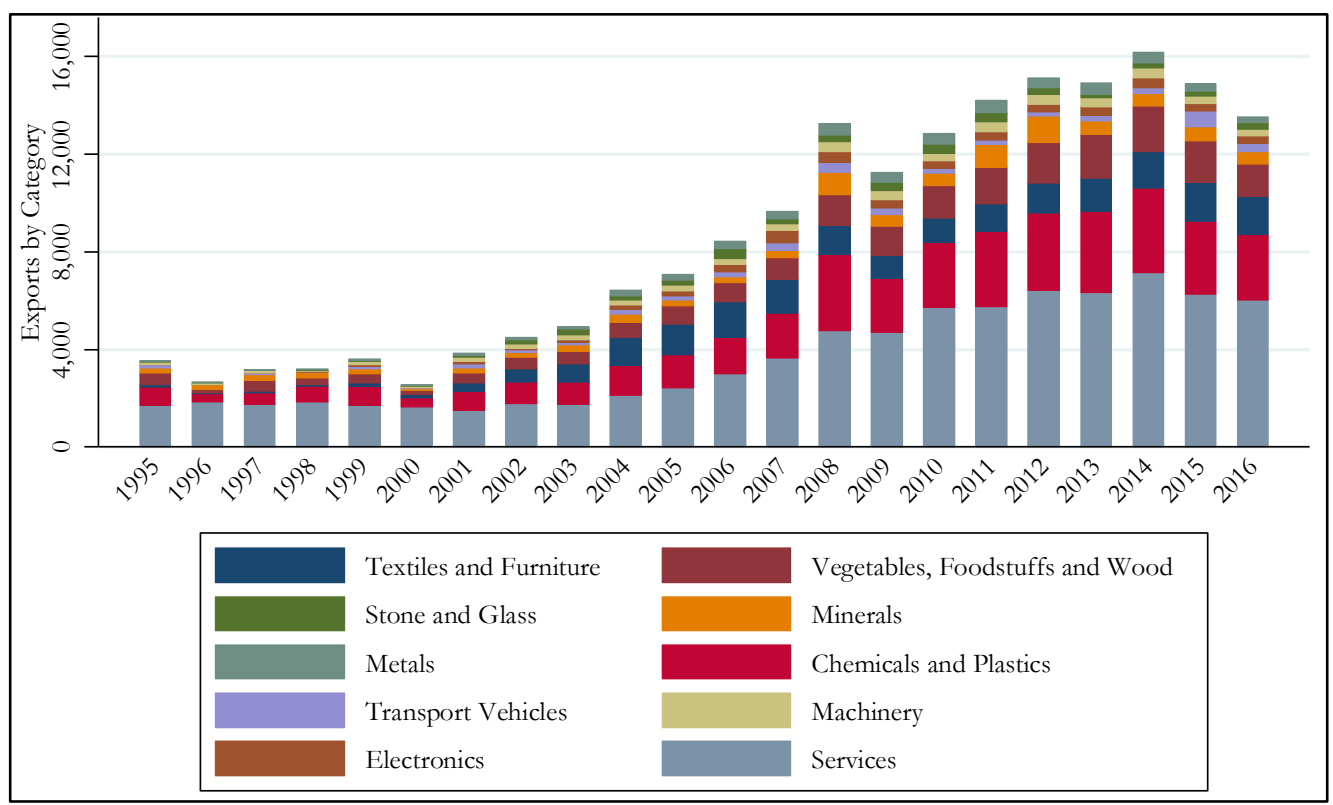

Source: Own calculations based on the Atlas of Economic Complexity.

In order to incorporate services into Jordan's complexity profile, we used the Dun \& Bradstreet database (2015), which has representative employment information with broad international coverage and high industrial disaggregation for both goods and services. In doing so, some significant adjustments and adaptations to the original methodology were required.

We estimate the productive capacities of a place - either country or establishment according to its relative intensity of employment in different industries. In doing so, we assume that the combination of capital and labor used to develop a certain industry is similar across countries. Proximity metrics between two industries are computed based on the probability of co-production, both at the country and at the establishment level: Two products require

\footnotetext{
10 Travel, tourism, transportation and logistics delivered the bulk of this growth. At the same time, Jordan has increasingly emerged as a hub for activities related to information, communications and technology.
} 
similar capabilities if we observe with a relatively high frequency that they are manufactured (or rendered, in the case of services) within the same country, or within the same establishment. Based on these proximities, we construct the Industry Space (Figure 22). Each node represents an industry, and the lines connect them to those industries that are relatively adjacent from a technology standpoint. Different colors illustrate the sectors of the economy, which tend to cluster.

Figure 22. Industry Space (2015)

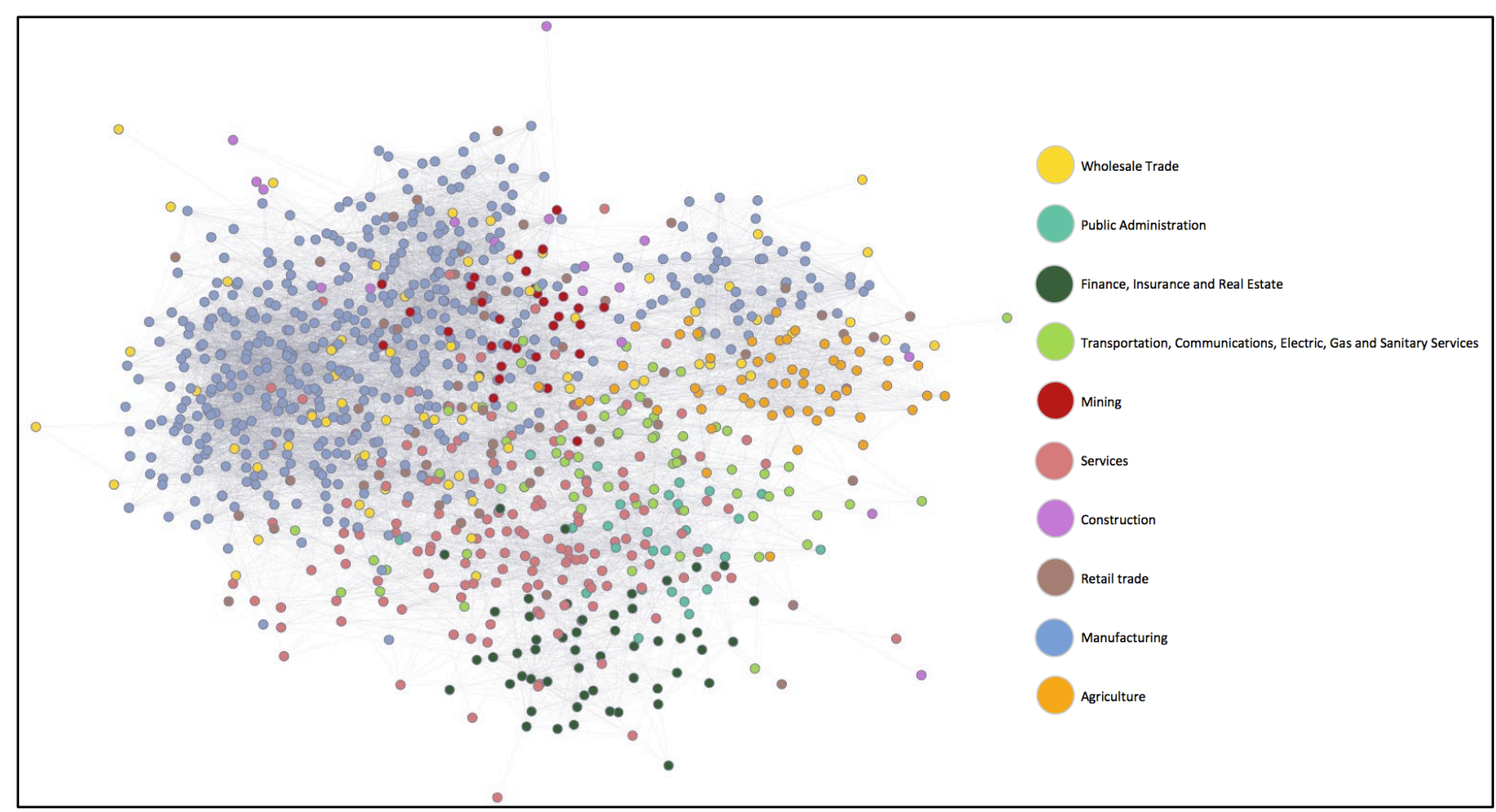

Source: Own calculations based on Dun \& Bradstreet (2015).

Jordan's relative position on the Industry Space is shown in Figure 23, where we have highlighted in colors those industries in which the country exhibits Revealed Comparative Advantage (RCA), i.e. that its share of employment in the industry is higher than the share of that industry in world employment. In general, we can conclude that it is somewhat sparsely populated and concentrated in manufacturing and wholesale trade (blue and yellow). Although a large part of the country's presence in the Industry Space is shown by these categories, in relative terms, Jordan exhibits a high presence in other industries such as, public administration; transportation, communications and public utilities; and finance, insurance and real estate. 
Figure 23. Jordan: Orientation in the Industry Space (2015)

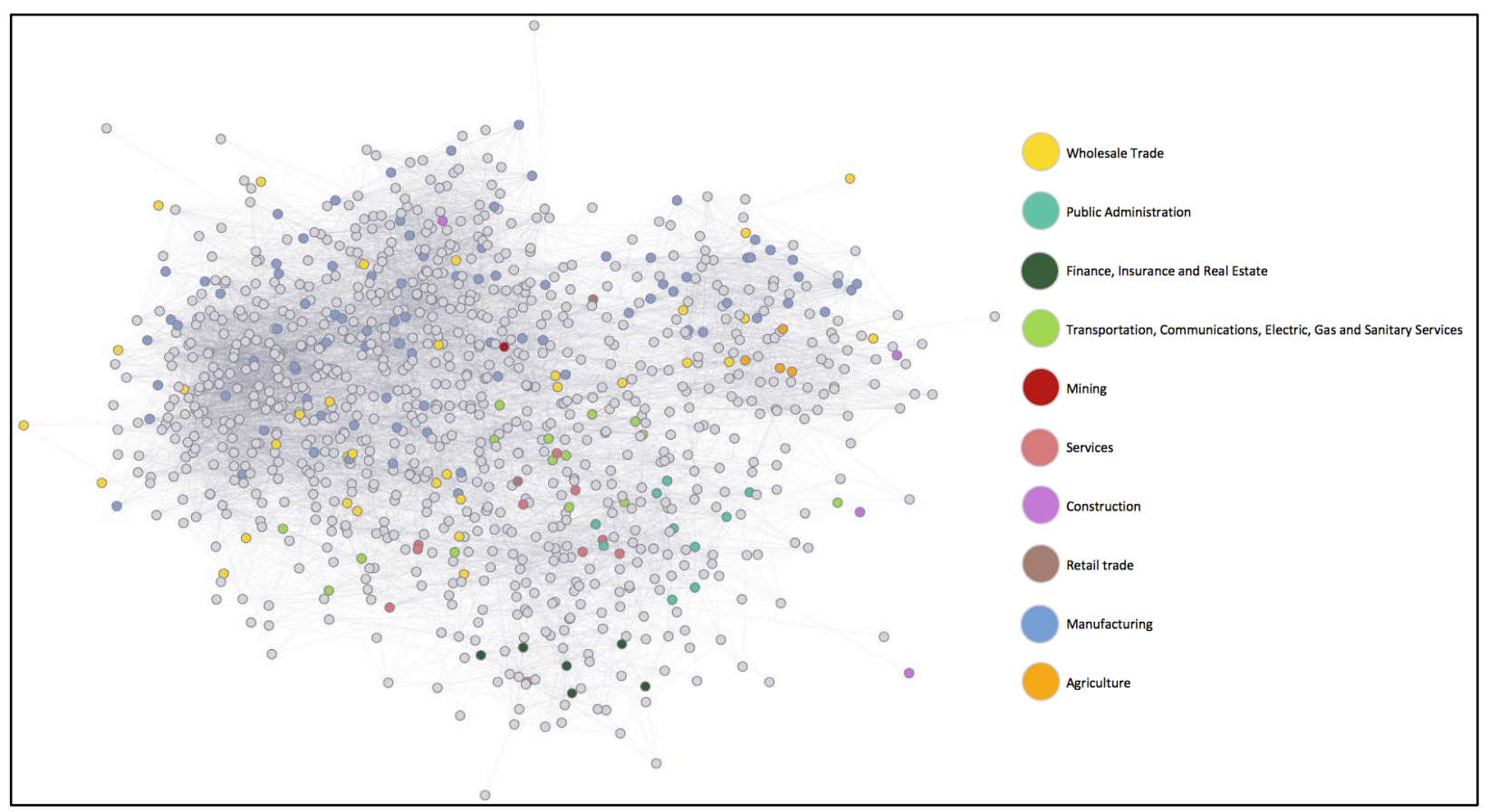

Source: Own calculations based on Dun \& Bradstreet (2015).

\subsection{Identifying sectors with high potential}

Our aim throughout this exercise is to provide policy makers with a roadmap for export diversification that may lead to rethinking targets for Jordan's productive development policies. Ultimately, industries to be targeted should emerge from an iterative and dynamic process carried out jointly by the public and private sectors, taking into account the stock of productive knowledge, considerations of shifting comparative advantages described above, and the particular constraints that might be hindering growth for the country in general, or some of these sectors in particular.

Figure 24 summarizes the specific process we followed in order to identify and prioritize Jordanian high-potential industries. In general, it relies heavily on the theory of economic complexity, which offers analytical rigor and impartiality. However, it also considers other relevant factors that influence the viability and desirability of the various options. Among them, some are specific to Jordan - such as attempts to fully exploit the country's competitive advantages and to avoid - whenever possible - the most binding constraints. It is here where the connection between growth diagnostics and complexity analysis becomes particularly significant. 
Figure 24. Sector Identification / Validation Process

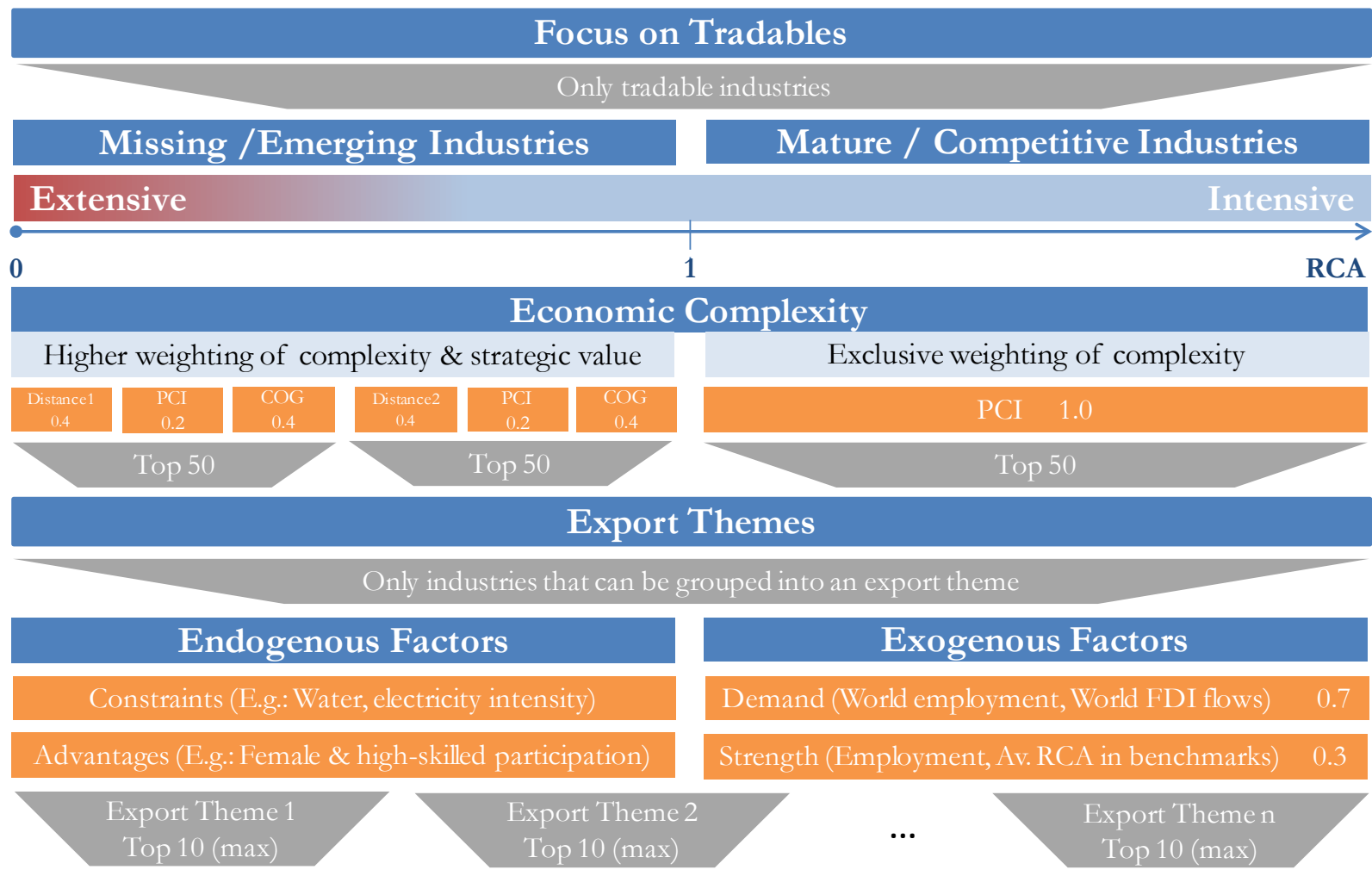

Initially, the process selects those industries that can be regarded as tradable, ${ }^{11}$ a focus that is far from arbitrary. Given the prospects of continued fiscal consolidation in Jordan, growth cannot depend on fiscal stimulus. The fact that the current account deficit is already large also means that growth cannot be led by increases in domestic private demand for non-tradable goods, since these will require more imports that would worsen the external balance. As stated before, Jordan's growth strategy must therefore be driven by exports and investments that either directly or indirectly support export growth. Jordan's abilities to achieve sustainable and inclusive export-led growth will depend on its ability to maximize the potential of existing industries (the intensive margin), and to attract new business models that build on Jordan's existing knowhow and capabilities (the extensive margin).

11 For the purposes of this work, the industries belonging to the Wholesale Trade, Resale Trade, and Public Administration divisions (SIC1) are considered non-tradable. So are the ones belonging to the following major groups (SIC2): Personal Services, Local \& Interurban Passenger Transit, Real Estate, Membership Organizations, Social Services, Private Households, and US Postal Service. All other industries (apart from Federal Reserve Banks) are regarded as tradable and, therefore, selected for the next steps of the process. 
Once a "tradeable" pool of industries is identified, industries are further selected based on economic complexity metrics. This is the cornerstone of the methodology: it is at this stage that we define what industries will be prioritized. The main goal is to identify nearby industries that can leverage on the know-how already in place in order to advance on a path towards greater levels of complexity and development. There is, however, an important tradeoff that most places usually face in the context of this exercise: the most complex industries or those with the best strategic positioning on the Industry Space tend to be further away from existing capabilities, while less complex industries tend to be closer.

In view of this tradeoff, the methodology tries to balance these different considerations by assigning positive weights to three different metrics. On the one hand, the "distance" variable (the inverse of proximity), measures how similar these industries are in terms of know-how to those already present in the country. On the other hand, the "product complexity index (PCI)" variable measures how complex or sophisticated a certain industry is. Finally, the "complexity opportunity gain (COG)" variable measures the extent to which a particular industry can lead the way to other, more complex industries (strategic value).

Given the need to diversify Jordan's exports into industries of higher economic complexity, in weighing the different complexity metrics, we have placed greater importance on absent industries (the extensive margin) that are above the current complexity average. Specifically, PCI and COG, are assigned a 60\% weight, while distance is given the remaining 40\%. For industries where Jordan currently exhibits relative intensity of employment (RCA) -the intensive margin - the distance indicator is zero; their strategic value has already been captured (the country is "already there"). Therefore, on the intensive margin, only PCI is considered.

Thanks to the granularity of the Dun \& Bradstreet dataset, co-production patterns for calculating distances between industries can be measured at several levels. However, due to limitations in database availability, the particular level where the indicator has a stronger capacity to predict diversification trajectories of countries is not entirely evident. ${ }^{12}$ For this reason, the methodology measures proximity at the country level and at the establishment level - and selects 50 missing/emerging industries in each case.

At this point along the process, the industries selected through the economic complexity filter - regardless of whether they are on the extensive or the intensive margin - and classified into groups of related industries. This process is facilitated by the existence of various classification systems, but it also involves some discretionary decisions. The groups that concentrate most of the selected industries are then aggregated into export themes.

\footnotetext{
12 To test that, several observations over time would be required. Unfortunately, CID currently only has access to the Dun \& Bradstreet database of one year (2015).
} 
The first type of the exogenous factor considered - and one that carries the heaviest weight - has to do with demand considerations. The theory of Economic Complexity is mainly supply-driven, based on the overlap between the productive capabilities required to develop a new industry and those that are already available. While these elements play a decisive role in determining an industry's probability of success, they say nothing about the its potential demand. Unfortunately, given the broader focus to include both goods and services in the analysis, no shared direct measure of demand is available. Therefore, we rely on indirect measures aimed at capturing the relative size of global demand for the different industries. The first one corresponds to total world employment, i.e. we assume that industries facing higher demand need to employ more people to meet it. ${ }^{13}$ Although a greater number of jobs may not always imply a higher demand, the risk of this not being so is expected to be low in the case of tradable industries, which are the focus of this analysis.

Our second proxy for demand is the world's flows of FDI. In this case, the rationale is that investors are more attracted to industries that are expected to face a higher demand. For the purposes of constructing this measure, information from the fDi Markets database was used. ${ }^{14}$ Although this information is available for a classification system different from the one used here, and for a less granular aggregation level, we developed a crosswalk that allows us to assign foreign direct investment flows to the industries of interest.

A second type of exogenous factor deals with the "strength" in Jordan's benchmark countries. The underlying logic is that if an industry has successfully developed in similar contexts, then it should be relatively more feasible in Jordan. A high level of strength does not guarantee the success of the industry, but it does make it more likely. Specifically, both total employment and the average RCA in benchmark countries are considered to measure this factor. Since it corresponds to a consideration of supply, a dimension that is already well-addressed, the strength factor is assigned a lower weight than the demand factor.

The demand and strength factors are exogenous to Jordan. However, there are other factors with the capacity to affect the viability of the different industries that are specific to the country (endogenous factors). Broadly speaking, export growth in Jordan should not only take advantage of world demand and specialization trends, but also rely on the country's comparative advantages. At the same time, it should avoid-at least initially-sectors that are intensive in factors identified as binding constraints for economic growth in Jordan.

\footnotetext{
13 This is a case in which the comparison between industries belonging to different subjects may be unfair because different sectors may require employment in different proportions. They may also be subject to different levels of representation in the database. It might still be unfair to compare industries within themes but the expectation is that the level "unfairness" in this case is lower.

$14 \mathrm{fDi}$ Markets is a from the Financial Times. See: https://www.fdimarkets.com
} 
As highlighted above, a highly educated workforce is one of the country's comparative advantages. In this context, the long-term increase of highly educated women has been particularly noteworthy. Our growth diagnostic also identified the high cost of energy and water scarcity as two of the most important binding constraints in Jordan. While this stage of the analysis has yet to be completed, the growth strategy will initially prioritize industries that tend to employ highskilled labor and women, as well as those that show a low intensity of reliance on electricity and water.

The industries that emerged from this analysis have been grouped into eight themes, ${ }^{15}$ which provide a roadmap for Jordan's structural transformation and export diversification over the next several years. Figure 25 describes the eight export themes, while Figure 26 identifies the industries within each theme that ranked the highest within the process described earlier. We have highlighted in bold the industries where Jordan has already revealed comparative advantages, but can continue growing (the intensive margin). The remaining industries are either non-existent in Jordan, or exhibit an intensity of employment that is smaller than what we would expect given their overall score.

Figure 25. Export Themes

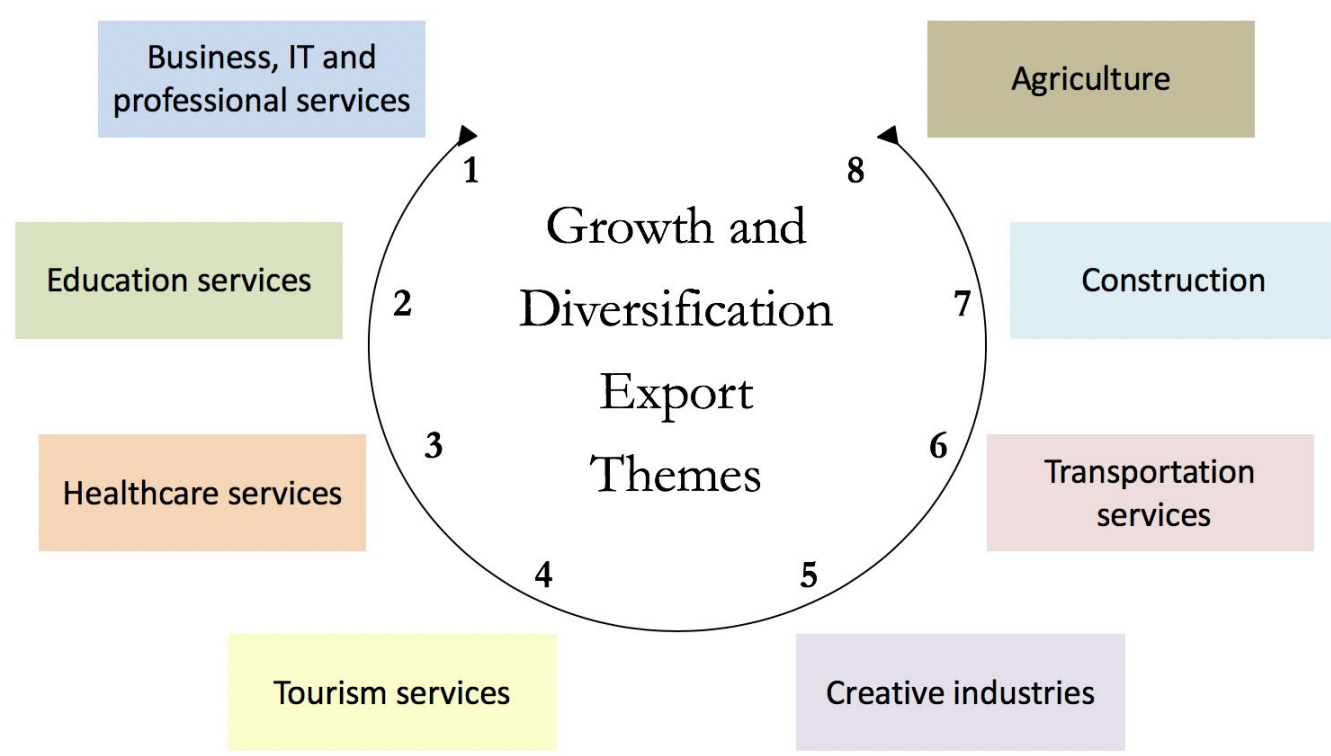

Figure 26. Jordan: Export Themes - Top 10 Industries

\footnotetext{
15 These themes were the ones that concentrated most of the industries selected based on the process described.
} 


\begin{tabular}{|l|}
\hline \multicolumn{1}{|c|}{ Business, IT and Professional Services } \\
\hline Offices of Holding Companies, n.e.c. \\
Engineering Services \\
Management Consulting Services \\
Accounting, Auditing, and Bookkeeping Services \\
Insurance Agents, Brokers, and Service \\
Building Maintenance Services, n.e.c. \\
Legal Services \\
Detective, Guard, and Armored Car Services \\
Help Supply Services \\
Advertising Agencies \\
\hline
\end{tabular}

Healthcare Services

General Medical and Surgical Hospitals

Health and Allied Services, n.e.c.

Offices and Clinics of Dentists

Specialty Hospitals, Except Psychiatric

Offices and Clinics of Health Practitioners, n.e.c.

Home Health Care Services

Medical Laboratories

Hospital and Medical Service Plans

Specialty Outpatient Facilities, n.e.c.

\begin{tabular}{|l|}
\hline \multicolumn{1}{|c|}{ Creative Industries } \\
\hline Television Broadcasting Stations \\
Newspapers: Publishing and/or Printing \\
Motion Picture and Video Tape Production \\
Radio Broadcasting Stations \\
Theatrical Producers and Misc. Theatrical Services \\
Periodicals: Publishing and/or Printing \\
Commercial Art and Graphic Design \\
Radio, TV, and Publishers' Advertising Representatives \\
Services Allied to Motion Picture Production \\
Commercial Photography \\
\hline
\end{tabular}

\begin{tabular}{|l|}
\hline \multicolumn{1}{|c|}{ Construction } \\
\hline Heavy Construction, n.e.c. \\
Special Trade Contractors, n.e.c. \\
Highway and Street Construction \\
Electrical Work \\
Plumbing, Heating and Air-Conditioning \\
Water, Sewer, and Comms, \& Power Line Construction \\
Carpentry Work \\
Ready-Mixed Concrete \\
Elevators and Moving Stairways \\
Flat Glass
\end{tabular}

\begin{tabular}{|l|}
\hline \multicolumn{1}{|c|}{ Educational Services } \\
\hline Colleges, Universities, and Professional Schools \\
Schools and Educational Services, n.e.c. \\
Junior Colleges and Technical Institutes \\
Vocational Schools, n.e.c. \\
\hline
\end{tabular}

\begin{tabular}{|l|}
\hline \multicolumn{1}{|c|}{ Tourism } \\
\hline Hotels and Motels \\
Amusement and Recreation Services, n.e.c. \\
Travel Agencies \\
Amusement Parks \\
Passenger Car Rental \\
Organization Hotels and Lodging Houses \\
Tour Operators \\
Rooming and Boarding Houses \\
Sporting and Recreational Camps \\
Museums and Art Galleries \\
\hline
\end{tabular}

\begin{tabular}{|l|}
\hline \multicolumn{1}{|c|}{ Transport Services } \\
\hline Trucking, Except Local \\
Airports, Flying Fields, and Airport Terminal Services \\
Rental of Railroad Cars \\
Air Transportation, Nonscheduled \\
Truck Trailers \\
Packing and Crating \\
Water Transportation Services, n.e.c. \\
Water Transportation of Passengers, n.e.c. \\
Courier Services, Except by Air \\
Refrigerated Warehousing and Storage \\
\hline
\end{tabular}

\begin{tabular}{|l|}
\hline \multicolumn{1}{|c|}{ Agriculture and Food } \\
\hline Bread and Other Bakery Products \\
Flour and Other Grain Mill Products \\
Chocolate and Cocoa Products \\
Sausages and Other Prepared Meat Products \\
Poultry Slaughtering and Processing \\
Natural, Processed, and Imitation Cheese \\
Ice Cream and Frozen Desserts \\
Beet Sugar \\
Dried \& Dehydrated Fruits, Vegetables, Soup Mixes \\
Meat Packing Plants \\
\hline
\end{tabular}

Source: Own construction based on Dun \& Bradstreet and fDi Markets. 


\section{Integrating these elements into a framework for a growth strategy}

Today, Jordan is facing a challenging situation that is once again testing its resilience, strength, and national character: this is not the first time and - given the history of the region will most likely not be the last. Back in 1999, when Abdullah II became King, the country faced a similar set of challenges. The region's economy was suffering from the fallout of Iraq's invasion of Kuwait. Most Gulf countries dramatically cut back on their loans, grants, and investments in Jordan, and the crisis also put a strain on remittances. The imposition of sanctions on Iraq disrupted not only trade with a critical export market, but also the supply of oil that Jordan had been receiving on concessional terms. Growth, which registered an average of 7.1\% between 1990-1995 (2.0\% per capita), slowed to $2.9 \%$ between $1995-1999$ (0.6\% per capita). The government had to rely on foreign borrowing, driving debt-to-GDP ratios up to $100 \%$ by the end of 1998 .

Jordan managed to adapt and emerge from this challenge in a stronger economic position than ever before. It did so through an aggressive combination of fiscal consolidation, international financing - a program with the International Monetary Fund and a rescheduling of its debt payments with the Paris Club - and an aggressive export-based growth strategy (leveraged through admission to the World Trade Organization in April, 2000). This three-pronged strategy launched Jordan into a period of accelerated growth - described in the first section of this paper - which saw exports of goods and services triple over 2000-2008, and income per capita grow a cumulative $34.3 \%$ over the same period. Jordan achieved this transition by evolving its own policies to respond to a changing world, and thanks to collaborative support from the international community.

Today, Jordan faces a set of challenges that are similar in nature, but much larger in magnitude. A sequence of large and persistent shocks - the global financial crisis, the Arab Spring, the Syrian refugee crisis, and the Daesh conflict in Iraq - have thrown its economy out of balance. As was the case in previous crises, the country relied on issuing foreign debt to support government spending, driving debt-to-GDP ratios from 55\% in 2009 to 94\% by the end of 2017. In 2012, Jordan entered into a Stand-By Agreement with the International Monetary Fund (IMF), which turned into an Extended Fund Facility in 2015. With the support of the IMF, Jordan implemented several significant reforms aimed at reducing the public deficit. A large fiscal consolidation has taken place, mostly driven by indirect taxes, elimination of subsidies, and large cuts in public investment.

In spite of the large fiscal adjustment, a number of factors have caused Jordan's debt-toGDP ratio to remain constant. One is the fact that Jordan needed to issue significant amounts of foreign debt between 2011 and 2015, which suggests that the IMF program was underfunded. As a consequence, Jordan had to resort to international financial markets at a time when its economy was far from stabilized, which resulted in high yields. A second factor is the current account deficit, which has remained persistently large and has continued to widen since 2014, even in spite of the 
tightening of the fiscal deficit. Furthermore, the procyclical fiscal response - tightening fiscal expenditures in a decelerating economy - depressed growth further, and at a time when Jordan has taken on the extraordinary additional burden to its government services and labor market functionality that comes from hosting more than one million refugees.

Despite significant efforts, the need for fiscal consolidation is likely to continue. In order to rein foreign debt in to a sustainable path, Jordan must pursue an international financial strategy aimed at reducing the cost of funds, while promoting a more aggressive growth strategy. Given the prospect of continued fiscal restraint, the growth strategy cannot depend on domestic demand, but must instead be led by exports and investments that directly or indirectly increase exports. In order for the non-tradable economy to expand, Jordan must expand its exports while adapting to a domestic, regional, and global economic landscape that has changed considerably since its previous export boom. The previous period of high growth and export expansion (2000-2008), was mostly led by exports which relied on low-skill sectors that created little employment for Jordanians (garments and agriculture) and/or relied on low-cost energy (basic chemical products). These drivers of past export growth are poorly matched with the comparative advantages in factor endowments that Jordan enjoys today.

Our proposed path forward for Jordan is summarized in schematic form in Figure 27. In order to fully understand the growth opportunities of the tradable economy, it is important to recognize the characteristics of the associated labor market. Employment in the tradable economy is a mix of low-skill jobs, primarily focused around goods exports, and higher-skill jobs, which gravitate more towards service exports. A high proportion of low-skill jobs in the tradable economy are currently filled by non-Jordanians and tend to pay below-average wages, whereas high-skill jobs pay higher wages and are largely filled by Jordanians. The country currently has surplus labor - as evidenced by the high unemployment rates - among its growing supply of highly educated individuals, especially women, and among its supply of less educated foreigners, in particular, Syrian refugees.

Jordan must channel its policies and international support in ways that will help all parts of the tradable economy grow, but it is especially important that attention be placed on those parts of the tradable economy that can support higher wages. High-wage, tradable jobs provide a direct boost to demand for non-tradable goods and services because more of those wages end up paying for retail, restaurants, travel and transportation services in the non-tradable economy. While the high-wage jobs are strategic because they can absorb higher rates of female labor, the spillover benefits in the non-tradable economy are especially important for expanding flexible work opportunities to lower-skilled workers, including refugees. 
Figure 27. A Schematic of Jordan's Growth Strategy

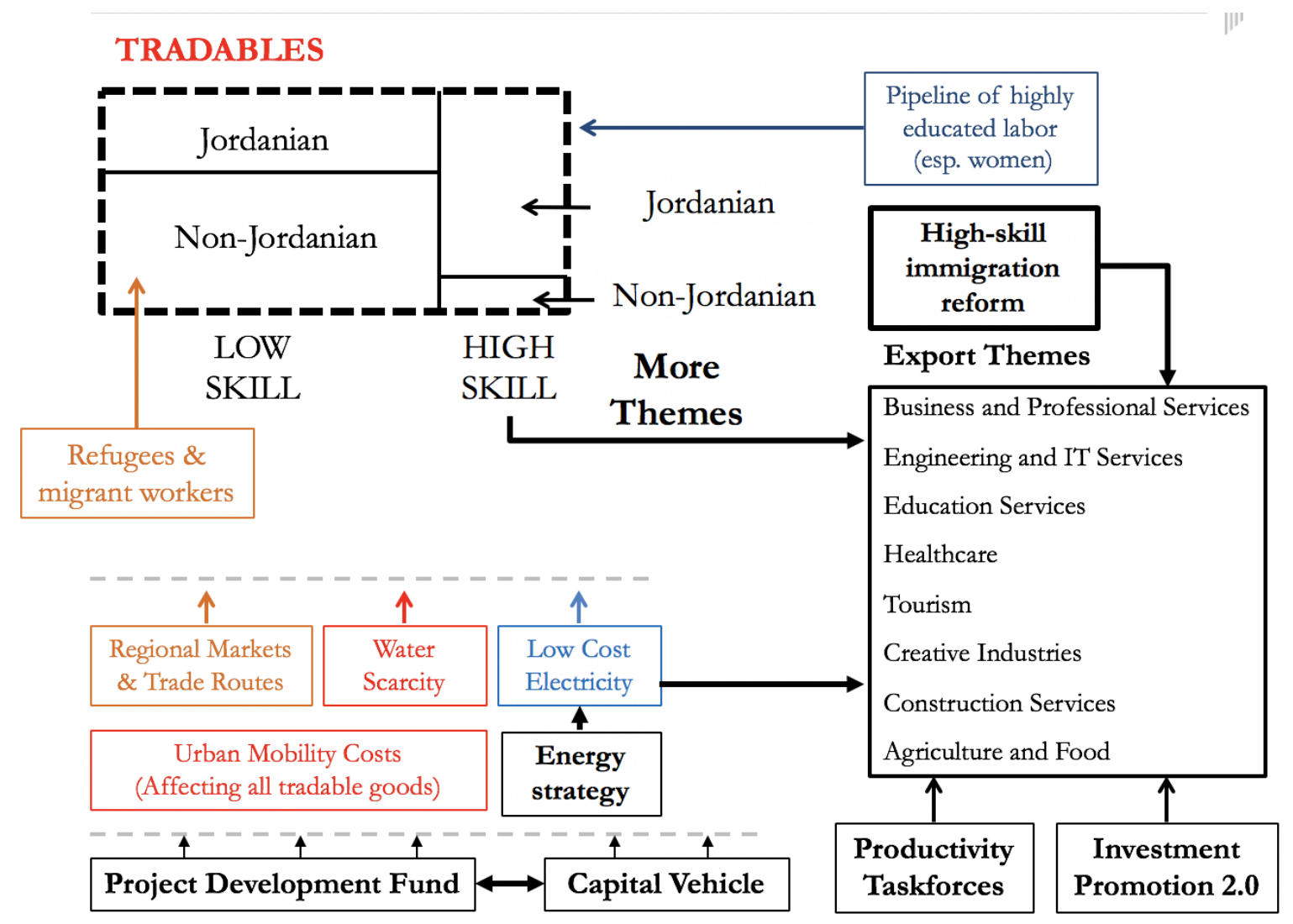

Jordan's comparative advantages in exports are influenced by domestic constraints and opportunities, as well as by conditions in the region and in the global economy. Policymakers must be aware of these factors, and must use this knowledge to solve priority constraints that have left latent comparative advantages unfulfilled, as well as taking advantage of new opportunities that emerge as conditions change. One significant constraint - as discussed in this paper - is the high cost of electricity. Presently, new opportunities are emerging that can release Jordan from this constraint if it can manage to take advantage of its abundant natural resources for generating low-cost, renewable energy. Although this remains a critical component of Jordan's medium-term growth strategy, in the shorter term, exports should expand in activities that are less intensive in the use of energy and electricity.

Though not discussed in this paper, there are two other significant constraints for Jordan mentioned in Figure 27. The first one is the overall scarcity of water, and its high cost as a factor of production, mainly driven by the cost of electricity to pump it. The second are inefficiencies in urban mobility stemming from weak public transportation systems. Poor 
quality public transportation in urban centers translates into higher costs of labor across nearly all economic activities and forces companies that need to remain globally competitive to cluster around narrow geographical areas (such as around King Hussein Business Park in Amman or near the Jordan University of Science and Technology outside Irbid) to access the labor they require.

The Economic Complexity analysis described in Section 5 - which, for the first time we have made to include service exports - quantitatively explored which export themes are most strategic for Jordan and took into account considerations of the comparative advantages and disadvantages described above. The analysis identified eight export themes as most strategic given the capabilities exhibited by the Jordanian economy as well as global trends in demand. Industries at a detailed level emerged in the following themes: (1) Business, IT and Professional Services, (2) Education Services, (3) Healthcare Services, (4) Creative Industries, (5) Tourism, (6) Transportation and Logistics, (7) Construction Materials and Services, and 8) Agriculture and Food Processing. These industries range from those that already have a revealed comparative advantage, to those that either do not yet exist in Jordan, or exist with a much lower intensity than would be expected, given Jordan's present capacities and know-how. Maximizing opportunities for growth across this spectrum demands a mix of government actions and international support.

The majority of these export themes represent activities that are intensive in highly educated labor, and are not intensive in water or electricity. Such is the case for Business, IT and Professional Services; Education Services; Healthcare Services; Creative Industries; and Construction Materials and Services in particular. Unfortunately, all of these high-skill service industries face a pressing, self-inflicted constraint in the form of current immigration policies. For these industries to thrive, firms must be able to access global talent. As described in Section 4.3, easing access to foreign talent will not result in reduced job opportunities for Jordanians in these industries; much to the contrary, it will allow them to expand significantly, creating many more Jordanian jobs than foreign jobs. If this were not the case, then firms today would not be trying to enter Jordan to take advantage of the talents and cost advantages that Jordanian labor provides.

These export themes also overlap in widespread opportunities for benefiting the region. Business, IT and Professional Services present an opportunity for Jordan to rapidly expand as a hub for multinational companies' back-office services, and to serve as a launching point for global companies' entry into the Middle East. As neighboring countries emerge from conflict, Jordan is also poised to become a purveyor of services (construction, healthcare, education) across these themes, and even lead the way in the creation of IT-enabled innovations that may solve pressing problems for the region.

Other export themes such as Tourism; and Agriculture and Food Processing, exist further along the low-skill and lower wage end of the spectrum. The expansion of these themes would imply job growth that is more evenly spread between Jordanians and 
foreigners. In the short term, these themes will continue to face more disadvantages in the form of high water and electricity costs, since they are more intensive in these inputs than the other themes. Nevertheless, these industries remain extremely important in terms of export volumes, overall employment, and the inclusiveness of growth across all of Jordan's various regions. Over the past few years, Jordan has seen tourism promotion efforts pay off as the area's stability improves somewhat, but much more growth is possible ahead. Agriculture and food exports, on the other hand, took a significant hit due to regional shocks in recent years. Long-term growth in this theme may require new private sector actors and creative government efforts to build value chains that are less reliant on the region, as well as innovating strategies for adapting to long-term challenges like water scarcity and newer challenges brought on by climate change.

Beyond the specific constraints faced by each theme and by different industries within each theme, there are three broad ways that the Government of Jordan can support a transformation in growth: (1) active and targeted investment promotion; (2) improved mechanisms for public-private collaboration toward solving industry-specific problems; and (3) improved capabilities for prioritizing and delivering public investment projects.

For high-potential industries that either do not exist or exist with a low intensity, we recommend targeting investment promotion efforts around these eight export themes and focusing government resources on targeting high-likelihood companies based on their past investment decisions and stated business objectives. The task should fall upon the shoulders of the Jordan Investment Corporation (JIC), and may require generating new resources and a new institutional mindset in order to continuously and iteratively engage with prospective investors to facilitate new FDI.

In order to promote faster growth within existing sectors, we recommend instituting new and stronger mechanisms for public-private problem-solving of industry-specific issues. One tool for this that is used in other countries but that has been underutilized in Jordan is the presence of "Productivity Taskforces:" working groups made up of private and public sector individuals that meet regularly to identify the most binding constraints to the full potential of key industries. Such working groups, focused on a number of the eight identified export themes, could significantly accelerate the growth of existing industries by revealing constraints to productivity growth that may remain hidden to the government unless it collaborates with the private sector.

Finally, despite available financing for a number of large-scale public infrastructure investments, Jordan exhibits a pattern of slow development of necessary infrastructure, including in water, energy and transportation. Moving forward, the Government of Jordan must develop new capabilities to prioritize, advance, and finance bankable infrastructure projects. Such capacity is essential to support the mobilization of private capital and improve the efficiency and expediency of public investment. There have been a number of institutional 
arrangements developed in other countries, as well as sub-nationally in Jordan, which could be leveraged at the national level for these purposes.

Promoting exports and export-related investment through these various efforts will have spillover impacts into the non-tradable sector, an impulse that today cannot come out of the fiscal budget. Faster growth, together with an international financing strategy aimed at reducing the cost of funding - preventing Jordan from issuing debt in the international markets while its economy fully stabilizes - are the key elements to pull the economy out of the crisis and embark the country on a path of sustainable growth. 


\section{Figures}

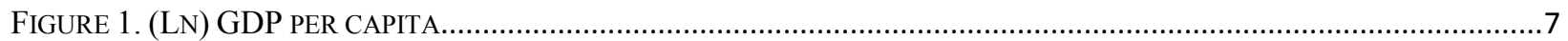

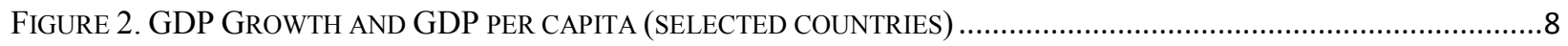

FIGURE 3. CONTRIBUTION TO GDP GROWTH BY SECTOR (PERCENTAGE POINTS) ……...........................................

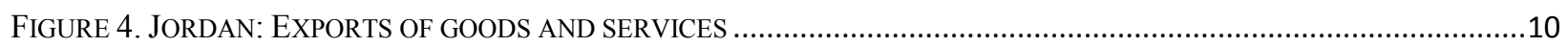

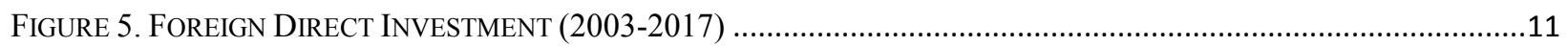

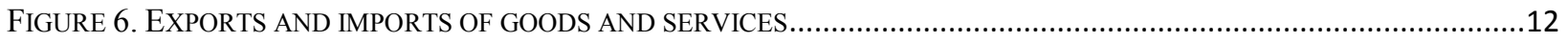

Figure 7. CuRrent ACCount Defict, FDI, AND ForeIgn Public DebT ……..................................................13

FIGURE 8. JORDAN: BUDGETARY FISCAL BALANCE (2005-2017) …..........................................................................14

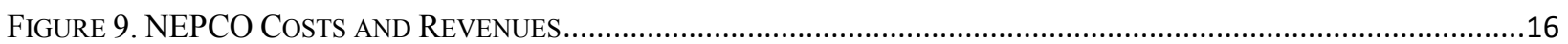

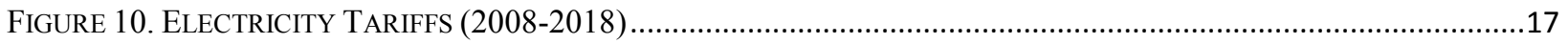

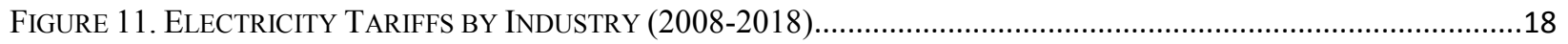

FigURE 12. SHARE OF MANUFACTURING VALUE ADDED BY ENERGY INTENSITY (2010) ......................................18

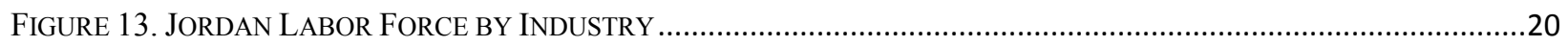

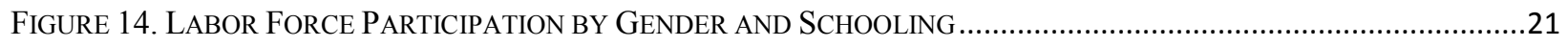

FIGURE 15. UNEMPLOYMENT BY LEVEL OF EDUCATION FOR JORDANIAN MEN AND WOMEN …..................................21

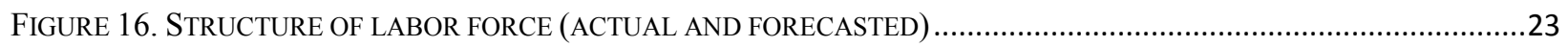

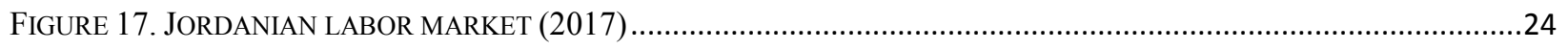

FIGURE 18. WAGE DifFERENCES OF FoREIGNERS VERSUS JoRDANIANS IN FOUR LARGE SECTORS ............................26

Figure 19. WAGE DifFERENCES OF ForEIGNERS VS. JoRDANIANS IN High-WAGE SECTORS ...................................27

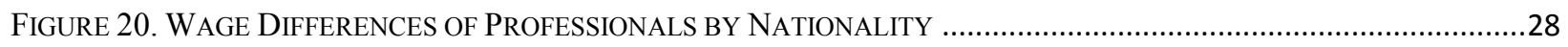

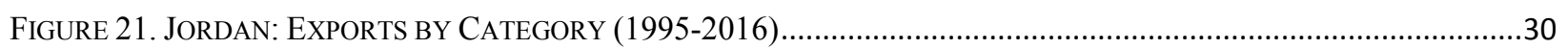

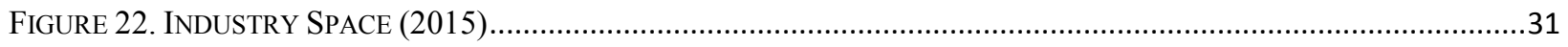

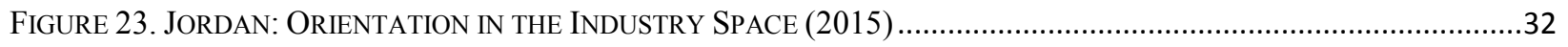

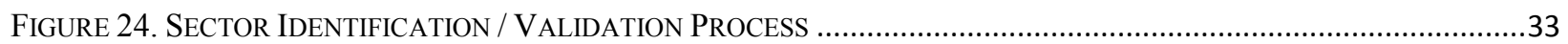

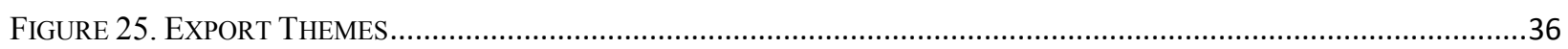

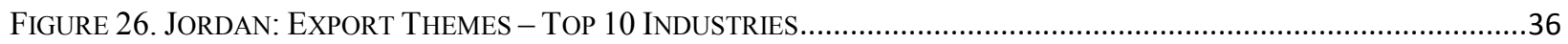

FIGURE 27. A SCHEMATIC OF JORDAN'S GROWTH STRATEGY …….......................................................................40

\section{Tables}

TABLE 1: PRIMARY FISCAL SURPLUS, GROWTH AND YIELDS NEEDED TO ACHIEVE 77\% OF DEBT-TO-GDP BY 2025 ....15 


\section{References}

Balassa, B. (1965). "Trade liberalization and revealed comparative advantage”. The Manchester School, Volume33, Issue2, May 1965, pp. 99-123

Hausmann, Ricardo, and Bailey Klinger (2006). "Structural Transformation and Patterns of Comparative Advantage", CID Working Paper.

Hausmann, Ricardo, Cesar Hidalgo, Sebastián Bustos, Michele Coscia, Sarah Chung, Juan Jimenez, Alexander Simoes, and Muhammed Yildirim (2011). "The Atlas of Economic Complexity". Puritan Press. Cambridge MA.

International Monetary Fund (2012). Jordan: Staff Report for the 2012 Article IV Consultation, May 22, 2012.

International Monetary Fund (2014). Jordan: Staff Report for the 2014 Article IV Consultation, Third and Fourth Reviews Under the Stand-By Arrangement, Request for Waivers of Nonobservance of Performance Criterion and Applicability of Performance Criteria, June 9, 2014.

International Monetary Fund (2017). Jordan: 2017 Article IV Consultation-Press Release; Staff Report; and Statement by the Executive Director for Jordan. June 24, 2017.

International Monetary Fund (2018). Jordan: Preliminary Macro-Framework. December $11^{\text {th }}$, 2018.

Kar, S., Pritchett, L., Raihan, S., and Sen, K. (2013). "Looking for a break: Identifying transitions in growth regimes". Journal of Macroeconomics, Vol. 38, pp. 151-166.

Wald, A. (1943). "Tests of Statistical Hypotheses Concerning Several Parameters When the Number of Observations is Large," Transactions of the American Mathematical Society, 54, (1943), pp. 426-482. 